ESRI

SURVEY AND

STATISTICAL

REPORT SERIES

NUMBER 105

JUNE 2021

\section{DEVELOPMENTS IN HEALTHCARE INFORMATION SYSTEMS IN IRELAND AND INTERNATIONALLY}

\section{BRENDAN WALSH, CIARÁN MAC DOMHNAILL AND GRETTA MOHAN}

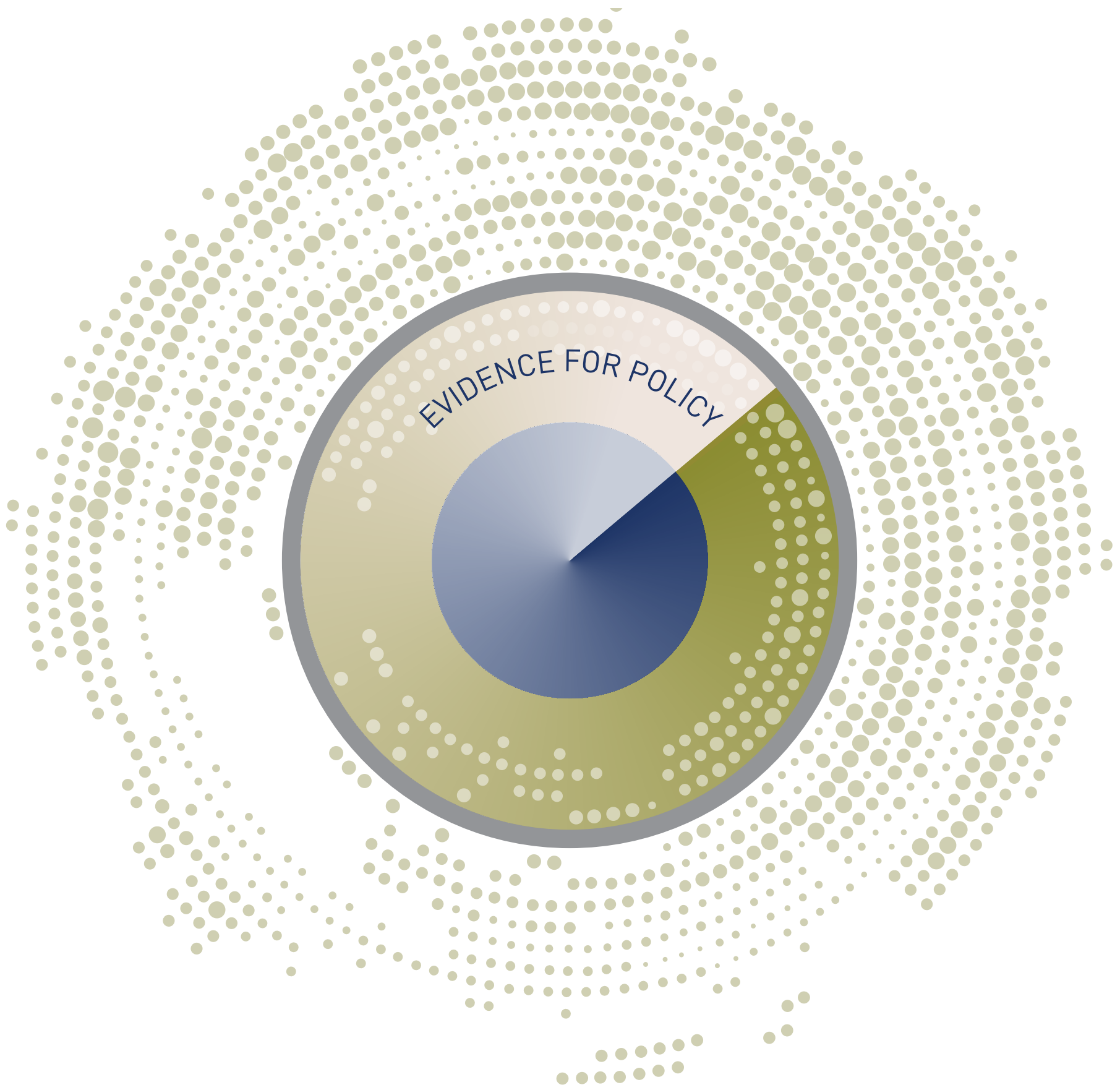




\section{DEVELOPMENTS IN HEALTHCARE INFORMATION SYSTEMS IN IRELAND AND INTERNATIONALLY}

Brendan Walsh

Ciarán Mac Domhnaill

Gretta Mohan

June 2021

\section{ESRI SURVEY AND STATISTICAL REPORT SERIES}

\section{NUMBER 105}

Available to download from www.esri.ie

(C) The Economic and Social Research Institute

Whitaker Square, Sir John Rogerson's Quay, Dublin 2

https://doi.org/10.26504/sustat105

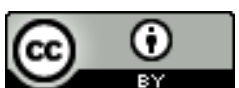

This Open Access work is licensed under a Creative Commons Attribution 4.0 International License (https://creativecommons.org/licenses/by/4.0/), which permits unrestricted use, distribution, and reproduction in any medium, provided the original work is properly credited. 


\section{ABOUT THE ESRI}

The mission of the Economic and Social Research Institute is to advance evidencebased policymaking that supports economic sustainability and social progress in Ireland. ESRI researchers apply the highest standards of academic excellence to challenges facing policymakers, focusing on 12 areas of critical importance to 21st Century Ireland.

The Institute was founded in 1960 by a group of senior civil servants led by Dr T.K. Whitaker, who identified the need for independent and in-depth research analysis to provide a robust evidence base for policymaking in Ireland.

Since then, the Institute has remained committed to independent research and its work is free of any expressed ideology or political position. The Institute publishes all research reaching the appropriate academic standard, irrespective of its findings or who funds the research.

The quality of its research output is guaranteed by a rigorous peer review process. ESRI researchers are experts in their fields and are committed to producing work that meets the highest academic standards and practices.

The work of the Institute is disseminated widely in books, journal articles and reports. ESRI publications are available to download, free of charge, from its website. Additionally, ESRI staff communicate research findings at regular conferences and seminars.

The ESRI is a company limited by guarantee, answerable to its members and governed by a Council, comprising 14 members who represent a cross-section of ESRI members from academia, civil services, state agencies, businesses and civil society. The Institute receives an annual grant-in-aid from the Department of Public Expenditure and Reform to support the scientific and public interest elements of the Institute's activities; the grant accounted for an average of 30 per cent of the Institute's income over the lifetime of the last Research Strategy. The remaining funding comes from research programmes supported by government departments and agencies, public bodies and competitive research programmes.

Further information is available at www.esri.ie. 


\section{THE AUTHORS}

Brendan Walsh and Gretta Mohan are Research Officers at the ESRI and Adjunct Assistant Professors at Trinity College Dublin. Ciarán Mac Domhnaill was a research assistant at the ESRI.

\section{ACKNOWLEDGEMENTS}

This research was commissioned and funded by Microsoft Ireland. The authors would like to acknowledge the contributions of clinicians, public-sector employees and academics who, to inform this work, shared their knowledge of the organisation of, and experience with, the Irish healthcare system. The time and feedback provided over the course of the production of this publication by internal and external peer reviewers is acknowledged. 



\section{TABLE OF CONTENTS}

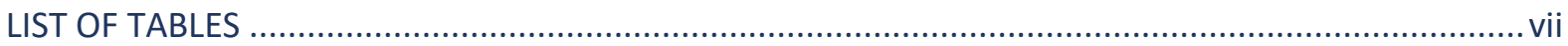

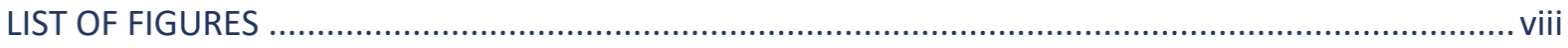

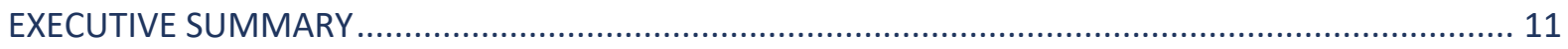

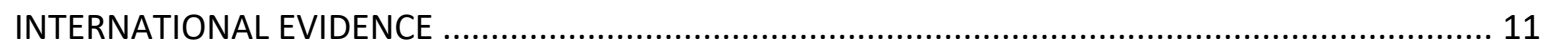

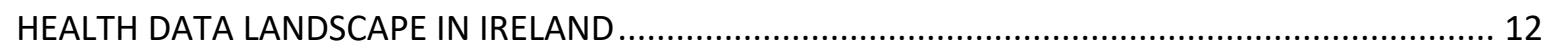

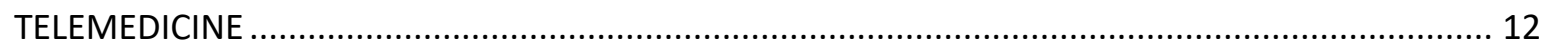

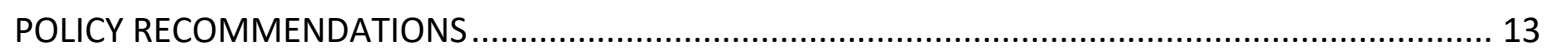

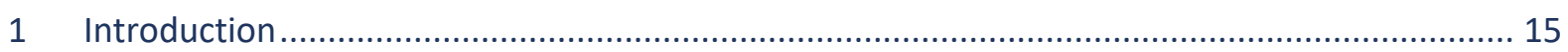

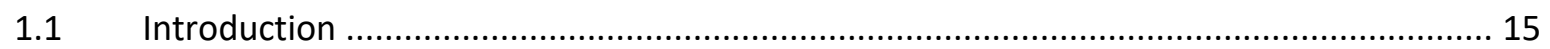

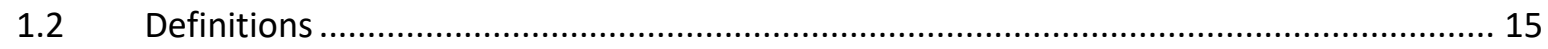

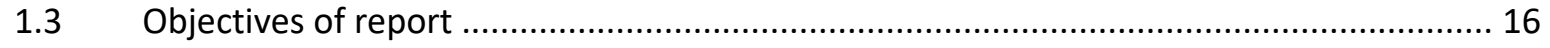

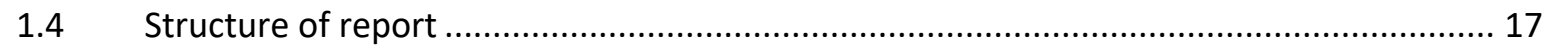

2 Health Information Systems in International Practice ............................................................... 19

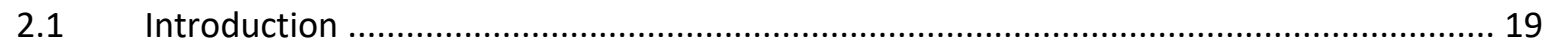

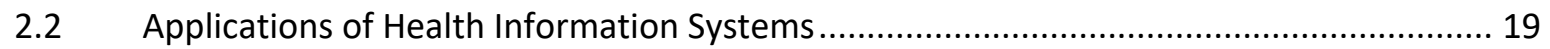

2.2.1 Using HIS and big data to learn, understand and inform decision-making.................... 19

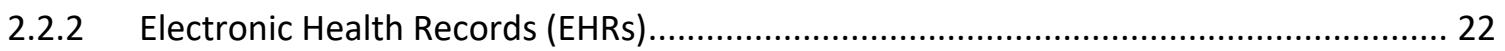

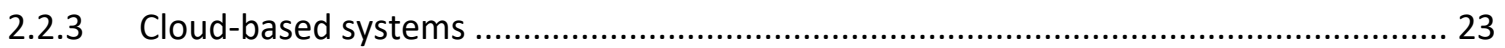

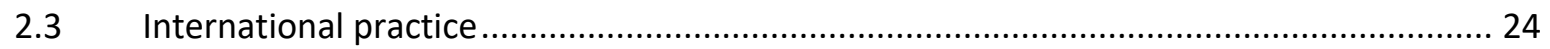

2.4 Health Information Systems and the response to COVID-19 ............................................ 29

2.4.1 Healthcare system response to public health emergencies ........................................ 30

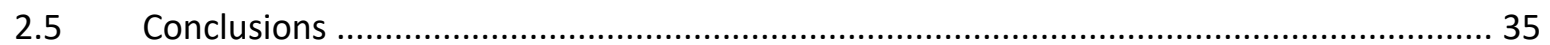

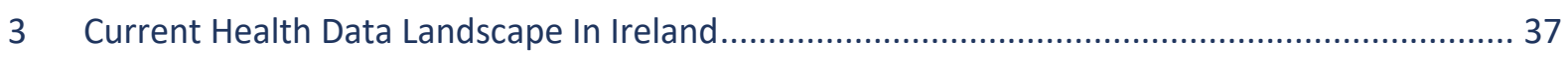

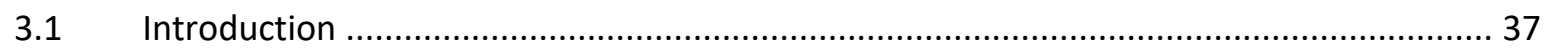

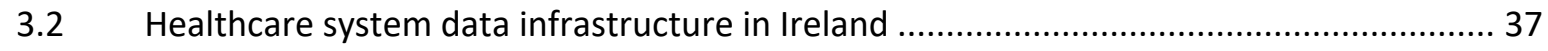

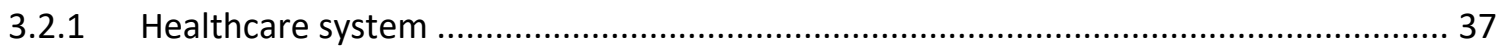

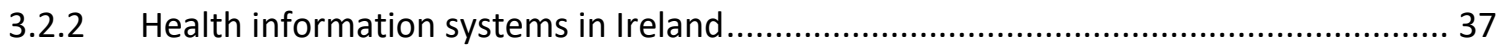

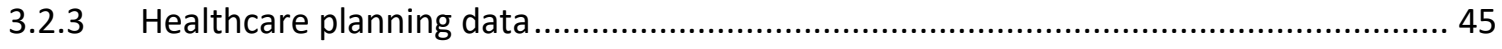

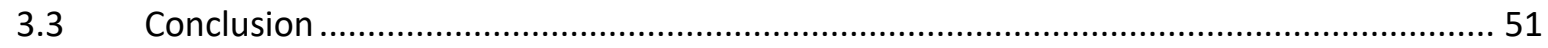

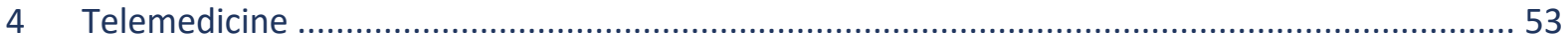

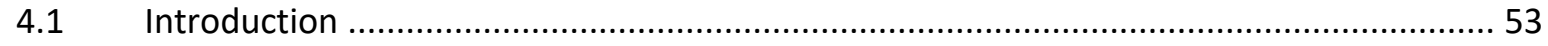

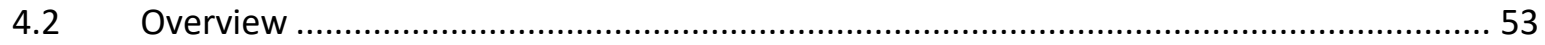

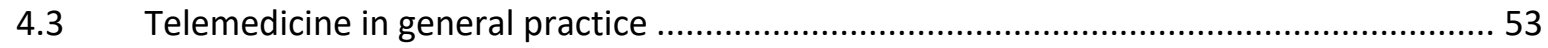

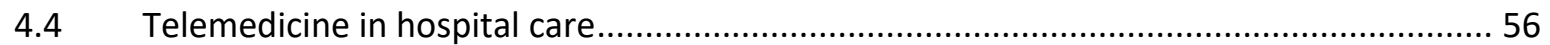




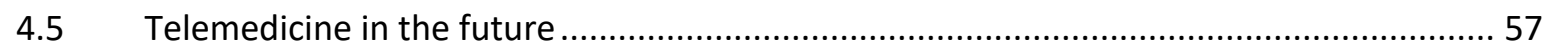

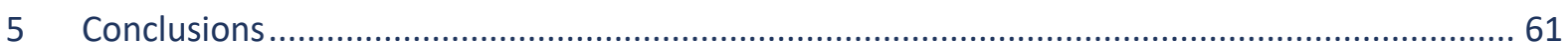

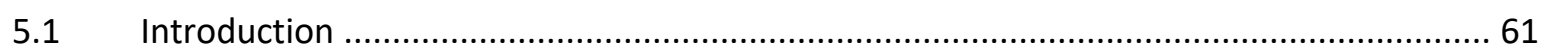

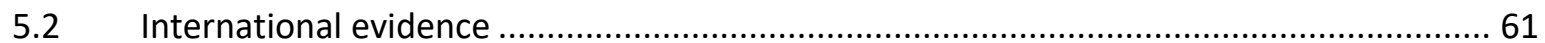

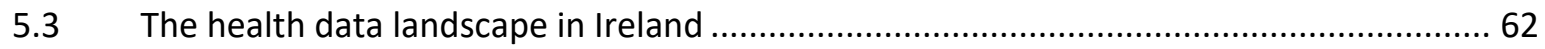

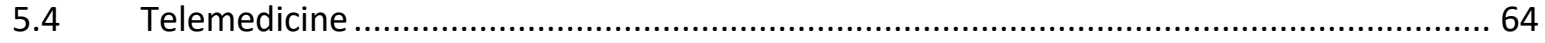

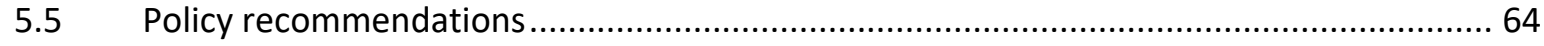

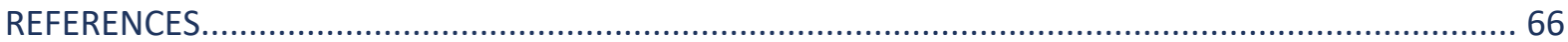




\section{LIST OF TABLES}

Table 3.1 HSE eHealth and ICT Budgets: 2017-2021 ............................................................ 40

Table 3.2 Comparison of admission counts, total bed days and mean Length of stay for a CIPPS and Spell (Busby et al., 2017) ............................................................................... 46 


\section{LIST OF FIGURES}

Figure 2.1 Electronic Health Record infrastructure ............................................................... 23

Figure 3.1 Electronic general referrals in Ireland per day: September 2019 - February 2021 ...... 44

Figure 3.2 Electronic referrals for cancer services in Ireland: 2009-2021................................. 45

Figure 4.1 General practice consultations in England: January 2020 - January 2021 ................... 54

Figure 4.2 General practice consultations across clinical commissioning groups in England: January

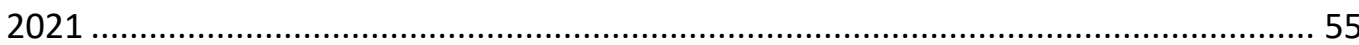

Figure 4.3 Breakdown of outpatient department (OPD) encounters of epilepsy patients by encounter type: 24 March 2020 to 24 June 2020 


\section{ABBREVIATIONS}

Al

CCGs

$\mathrm{CHI}$

CIPS

$\mathrm{ClO}$

COPD

CSO

EHR

ELSA

ESRI

EU

GDPR

GP

HCQIs

HIQA

HIPE

HIS

HPO

HPSC

HSE

ICGP

ICT

IEMAG

$\mathrm{IHI}$

ICU

IIS

LIS

ML

$\mathrm{MN}-\mathrm{CMS}$

$\mathrm{NHI}$

NHS

NOCA

NPHET

NICE
Artificial intelligence

Clinical Commissioning Groups

Community Health Index

Continuous inpatient spells

Chief Information Officer

Chronic obstructive pulmonary disease

Central Statistics Office

Electronic health record

English Longitudinal Study of Ageing

Economic and Social Research Institute

European Union

General Data Protection Regulation

General practitioner

Health Care Quality Indicators

Health Information and Quality Authority

Hospital In-Patient Enquiry

Health information systems

Healthcare Pricing Office

Health Protection Surveillance Centre

Health Service Executive

Irish College of General Practitioners

Information and communications technology

Irish Epidemiological Modelling Advisory Group

Individual Health Identifier

Intensive Care Unit

Immunisation Information System

Laboratory information system

Machine learning

Maternal and Newborn Clinical Management System

National Health Index

National Health Service (UK)

National Office of Clinical Audit

National Public Health Emergency Team (NPHET) for COVID-19

National Institute for Health and Care Excellence, UK 
OECD

OPD

PiSCES

RCTs

RCSI

TILDA

US

WHO
Organisation for Economic Cooperation and Development Outpatient department

Providing Individualised Services and Care in Epilepsy

Randomised controlled trials

Royal College of Surgeons Ireland

The Irish Longitudinal Study on Ageing

United States

World Health Organization 


\section{EXECUTIVE SUMMARY}

The development of health information systems (HIS) and the deployment of digital health solutions are strategic priorities for the provision of healthcare in Ireland. Increased healthcare use, growing healthcare expenditures, and the need to react in real time to public health emergencies such as COVID-19 necessitate a greater role for HIS and strong health data infrastructures so as to manage healthcare data efficiently across health systems.

Several policy frameworks have outlined aspirations for the adoption of key tools such as individual health identifiers (IHIs) and electronic health records (EHRs). Implementation of these at a national scale has yet to be realised. Technological developments in a range of areas, from telemedicine to cloud-based computing, have better facilitated the health systems' ability to respond to the COVID-19 pandemic and have demonstrated the potential of eHealth for patients and decision-makers, including clinicians, public health officials and policymakers. Many of the improvements and experiences in HIS and technological developments during COVID-19 offer an impetus for the use of these components to ultimately provide better care to patients and a more efficient way of delivering services.

This report considers features of HIS internationally, examines the current HIS and health data landscape in Ireland, and provides more focus on how one component, telemedicine, has been used during the COVID-19 pandemic.

\section{INTERNATIONAL EVIDENCE}

An exploratory review of international evidence concerned with the organisation of HIS and health data infrastructures highlights successful elements of arranging such systems across countries. We find that policymakers in Ireland can learn from systems developed in neighbouring countries. Scotland provides a useful template for Ireland in the development of a modern HIS within the public health system. A mandated unique patient identifier, the Community Health Index ( $\mathrm{CHI})$, has been established and integrated across the Scottish system. It is used as the fulcrum through which a broad HIS has developed and will continue to build upon. eHealth features such as eReferrals and e-Prescribing are also well established. In addition, a 'Safe Haven' approach has allowed for the safe and secure use of collated data by researchers to further understand optimal patient care.

The available evidence indicates that an integrated national EHR is a key enabler of the collection, secure storage and confidential communication of health information from disparate settings within a health system. Examples such as NHS Spine (England) and AORTA (the Netherlands) have been shown to be particularly 
effective. Integrating EHRs within cloud-based systems further improves the use and accessibility of such data. Countries such as Denmark and Estonia have empowered patients in the management of their health and healthcare by allowing them to have greater access to, and control of the use of, their data.

While features such as 'big data', EHRs and IHI are important, of equal importance to a modern HIS is the ability for different systems across the health system to communicate and integrate with each other. Countries with decentralised health systems (e.g. Canada), or with several systems unable to be integrated (NHS England), demonstrate that taking a holistic view of the health system (both public and private) is needed when designing a HIS that is fully robust and interoperable.

\section{HEALTH DATA LANDSCAPE IN IRELAND}

This investigation finds significant gaps in HIS and data infrastructure across the health system in Ireland. While the establishment of eHealth Ireland has led to many improvements, considerable investment and further advancements are required. We estimate that, in 2021, less than 0.8 per cent of the public health budget is spent on eHealth and health technologies, similar to previous years and lower than peer countries which spend up to 3 per cent of their healthcare budget on health technologies.

The COVID-19 pandemic has highlighted severe deficiencies in the Irish health data landscape, which presented substantial challenges for decision-making to provide rapid responses at the onset of the pandemic. On the other hand, the experience of the COVID-19 public health emergency has also provided the catalyst for the rapid introduction of many new health technology features to aid the response to the pandemic. Moreover, pre-existing eHealth tools, such as e-Prescribing and eReferrals, and telemedicine have been increasingly adopted and used over the pandemic period. There has been an advent of new technologies such as cloudbased data lake platforms to collect and collate COVID-19 data, the COVID Care Tracker, and the artificial intelligence-based Health Chatbot to triage suspected COVID-19 cases. The COVID-19 Tracker app was also widely used by the public. These innovations have become vital features of Ireland's response to the pandemic. Furthermore, an IHI has been rolled out through national programmes such as the COVID-19 vaccination programme. Further building upon and strengthening these improvements and successes will be required to continue to navigate the course of the pandemic and to meet the healthcare challenges of the post-pandemic era.

\section{TELEMEDICINE}

We shine a spotlight on how the COVID-19 pandemic has had a considerable impact on how people interact with the health system. In particular, telemedicine has proved a vital lifeline for healthcare access and delivery in Ireland and 
internationally. In Ireland, across primary and hospital care, telemedicine has become a key feature of healthcare utilisation.

\section{POLICY RECOMMENDATIONS}

The development of an adequate HIS in Ireland requires continued efforts. Some of the recommendations emerging from this review have the potential for relatively rapid implementation, while others are likely to entail longer-term projects. As technologies continue to evolve, so too will the potential of HIS. Recommendations from this report include:

- Developing a modern HIS based on national IHIs and EHRs that spans services and the public and private systems.

- A robust, structured and rigorous health data infrastructure that captures data from public and private providers to allow for resource, capacity and workforce planning.

- Continued investment in current and capital funding needed for HIS in Ireland. Replacement of antiquated healthcare technologies with devices that afford appropriate modern capabilities and functions.

- Ensuring privacy protections for data subjects and cybersecurity provisions. This process should be transparent and well communicated to the public.

- Supporting digital health literacy and capability among older people, those in rural areas, and those in lower socioeconomic groups.

- Training the healthcare workforce in the use of new technologies and eHealth. 
14 | Developments in Healthcare Information Systems in Ireland and Internationally 


\section{INTRODUCTION}

\subsection{INTRODUCTION}

The ability of a healthcare system to effectively and efficiently meet the demands of the population depends on the quality of the health information structures and systems on which it relies. Developing strong health information systems (HIS) and introducing eHealth are now key strategic priorities for most health systems (Colombo et al., 2020). It has been acknowledged by policymakers that Ireland lacks a HIS comparable with many of its European peers (HSE, 2013; 2015). Many countries in the European Union (EU) are spending 2-3 per cent of their total healthcare budget on eHealth and health technology. In the past, only 0.85 per cent of the public healthcare budget in Ireland was spent on these features (HSE, 2013). Therefore, in 2013, the HSE through its eHealth Strategy for Ireland set out to develop Ireland's HIS and eHealth capabilities (HSE, 2013). While improvements have occurred, as we will show in this report, the health system requires further development of eHealth and data infrastructure so as to match Ireland's European peers.

In many countries, the COVID-19 pandemic has acted as a catalyst for the rapid development of HIS and eHealth to support healthcare systems' response to the pandemic. In an urgent, fast-developing global health crisis, the ability to make quick and informed decisions is vital. However, where information structures are not adequate, the capability to make prompt and effective responses can be curtailed. The COVID-19 pandemic has highlighted previous failures to invest in and develop a HIS and data infrastructure centred on planning and providing appropriate healthcare and social care to the Irish population. However, as we discuss, it has enforced the use of health technologies and systems, developed in a short period of time, in order to understand and respond to the pandemic. Therefore, one outcome of the pandemic could be to accelerate the transition to a more future-ready, technology-embracing health system.

\subsection{DEFINITIONS}

In the literature, the lexicon used to describe and discuss HIS and healthcare technologies can be broad, and often difficult to understand. For the purpose of this report, we define the broad terms used throughout the report as follows:

- Health Information Systems (HIS): the systems and technology used across the health system to collect, collate, store and analyse medical and health utilisation data.

- Health Informatics: the use of information and communication technologies (ICTs) for health and in healthcare (Bath, 2008). 
- Information and Communications Technologies (ICTs): technologies that allow for communication of and access to information through telecommunications. Examples include electronic health records (EHRs), digital databases and videoconferencing technology.

- Electronic Health (eHealth): The integration of information and knowledge sources involved in the delivery of healthcare via information technologybased systems. This includes many features which could also be described as ICT.

- Cloud-based systems: online systems that allow for the digital storage of information such as EHRs.

- Electronic Health Records (EHRs): a digital record of a patient's interactions with different areas of the healthcare system.

- Big Data: the abundant health data amassed from numerous sources, including EHRs, medical imaging, genomic sequencing, payor records, pharmaceutical research, wearables, and medical devices (NEJM Catalyst, 2018).

- Telemedicine: the use of technologies to deliver healthcare remotely or at a distance (Wootton, 2001).

\subsection{OBJECTIVES OF REPORT}

This report provides a high-level overview of the current health data landscape in Ireland and identifies areas that merit specific emphasis to advance a futureprepared health system. While it concentrates on the healthcare setting of Ireland, many of the findings will be applicable more broadly. The scope of the overview is wide, and we will discuss throughout the report various aspects of HIS, data infrastructures and health informatics.

The report first provides an overview of available evidence on HIS, eHealth and data infrastructures across diverse health systems. We focus on components of other health systems that may be most relevant to informing policy development in Ireland. Where appropriate, we provide early evidence on how HIS and eHealth are being used in the response to the COVID-19 pandemic.

Secondly, the report discusses the HIS and health data landscape in Ireland. We highlight current deficiencies as well as recent improvements and responses to COVID-19. A case study on how one component of change, telemedicine, is changing how patients interact with the healthcare system is described.

In the concluding chapter, we provide policy recommendations on HIS, eHealth, and health data infrastructure for Ireland. These recommendations, informed by the analyses in the report, focus on both short- and long-term features that 
policymakers in Ireland may consider.

\subsection{STRUCTURE OF REPORT}

Chapter 2 provides a review of international literature on HIS and health data infrastructures. Chapter 3 describes the HIS and health data landscape in Ireland, including some of the changes that occurred during the COVID-19 pandemic. Chapter 4 examines the use of telemedicine, particularly in light of COVID-19 developments. Chapter 5 provides policy recommendations. 
18 | Developments in Healthcare Information Systems in Ireland and Internationally 


\section{HEALTH INFORMATION SYSTEMS IN INTERNATIONAL PRACTICE}

\subsection{INTRODUCTION}

This chapter defines health information systems (HIS) and eHealth components and outlines the application of HIS and eHealth in practice. A review of evidence from both academic literature and international practice discussing HIS and the application of health informatics across diverse national and healthcare financing settings is provided. The chapter focuses where possible on those aspects that are most relevant to the Irish health system.

\subsection{APPLICATIONS OF HEALTH INFORMATION SYSTEMS}

In the literature, HIS is the broad term applied to the technologies used to collect, collate and analyse health data. In this section, we highlight how these systems engender the use of 'big data' and care of complex-care patients.

The volume of big data generated in healthcare is now comparable to that stemming from sectors such as banking and transportation (Colombo et al., 2020). Modern HIS have extensive capabilities to collect and collate information on patients and populations, often in real time. These data can enable patients, clinicians and policymakers to make quick and evidence-based decisions. However, the healthcare sector has proved much slower at tapping into the potential offered by this data flow. In Ireland for example, the failure to fully leverage the potential of information contained in routine health data, such as electronic health records (EHRs), has been highlighted as a missed opportunity to improve healthcare services (HIQA, 2014).

\subsubsection{Using HIS and big data to learn, understand and inform decision-making}

Despite the vast quantity of health data that is now being recorded, the efficiency with which these data can be exploited to improve health outcomes is reduced by incompatible and inconsistent systems holding these data (Peng et al., 2020). Such systems have often been heterogeneously constructed over time (Peng et al., 2020). In a review of 32 studies of approaches to integrating health data from various sources and to collaboratively using this integrated data, Peng et al. (2020) found that substantial challenges to achieving this functionality remain. Therefore, while we discuss the usefulness of big data in this section, it is clear from the outset that having an effective HIS is equally, if not more, important to the use of these data to inform planning and patient care.

In addition to the large datasets now available, considerable improvements in the statistical analysis of these data have been made. While medical data cannot be fully exploited due to data access restrictions (Rieke et al., 2020), where allowed, machine learning (ML) and artificial intelligence (Al) are increasingly being used to 
inform decision-making. The evolution of these methods means that researchers can now try to solve problems of prediction, as opposed to parameter estimation (Mullainathan and Spiess, 2017). The possibility of using these methods that accompany big data is welcome. However, risks such as the naïve application of such techniques and algorithms and clear misinterpretation of results have been raised (Mullainathan and Spiess, 2017). Furthermore, the ability to make a prediction does not necessarily equate to effective decision-making by a policymaker, especially where the underlying assumptions of $\mathrm{ML}$, required to make said prediction, are not fully understood (Athey, 2017). A review analysed literature on the application of ML methods with data collected over time, mainly during routine clinical care, and its impact on the clinical management of patients (Clifton et al., 2015). Generally, no effects on health outcomes were found. Computerised systems designed to support clinical decision-making that are based on Al have also been studied in a number of randomised controlled trials (RCTs). In a recent systematic review of $\mathrm{Al}$ in these trials, only two of five studies found any significant difference in patient outcomes as a result of Al-based interventions, representing a limited evidence base (Cresswell et al., 2020). Therefore, while indepth data on patients and the ability to statistically analyse the data are welcome, they are not necessarily the panacea to better patient outcomes.

Big data can be seen as EHR-type data. They can also encompass clinical images. Positive results have been seen from digital image-based workflow systems. Such systems enable repetitive processes, such as medication preparation, to be automated (Marzal-Alfaro et al., 2020). One study investigated the impact of an image-based workflow system, which aimed to reduce risk in the medication process of chemotherapy by digitally guiding technicians through the compounding process. The authors found the system to be clearly effective in increasing safety (Marzal-Alfaro et al., 2020). In areas such as cancer detection, Al and digital-based image data are also now a common feature. In England, the National Institute for Health and Care Excellence (NICE) recently published research examining the viability of five $\mathrm{Al}$ technologies in making a clinical diagnosis of breast cancer from digital mammography images (NICE, 2021). The overall financial impact of adopting these Al technologies was unclear. However, experts discussed that the technologies had the capability of reducing the number of people needed to read mammograms, especially as the technology could be integrated within the current screening computing infrastructure (NICE, 2021).

Big data and Al techniques are being applied to the care of people in specific settings, such as nursing homes (Hamann and Bezboruah, 2020). These data allow for a 'network' of care services to be constructed to improve overall service efficiency (Niyirora and Aragones, 2020). The article suggests that healthcare managers could employ such a network, and that similar methods could be developed to build a network of symptoms for various conditions (Niyirora and Aragones, 2020). 
One area where big data have been increasingly used is in examining populations with complex care needs. These populations are heavy users of healthcare. Despite accounting for 5 per cent of patients, 51 per cent of hospital expenditure in NHS England is attributable to complex care (multimorbidity) patients (Dreyer et al., 2019). However, applying big data to try to identify the specific combinations of chronic illness and morbidity that contribute most to hospital expenditure has proven difficult (Stokes et al., 2021).

In addition to using data to understand complex-care patients, HIS features such as integrated health data structures have the potential to help identify population groups with complex needs, compare the performance of various treatments, increase the effectiveness of responses to public health emergencies, and help detect inefficiencies in the healthcare system (Colombo et al., 2020). For example, such structures are being used for targeted medical solutions for groups such as those with diabetes (Schüssler-Fiorenza Rose et al., 2019; Zhou et al., 2019). The majority of studies in a review of 109 studies indicated that HIS and analyses of big data can improve complex-care patients' outcomes (Dorr et al., 2007). It was found that they can support team-based care of chronic illnesses by improving communications and population management.

HIS can be used to develop an integrated care continuum to better manage chronic-illness patients outside of hospital specifically. While hospital IT systems are often well developed, care for people in the community requires coordination across services, which is virtually impossible without adequate HIS. Sláintecare, Ireland's strategy for healthcare reform, puts a clear emphasis on the need to change the model of care for those with chronic illness, and the importance of HIS and health technologies for doing so (Department of Health, 2019; Government of Ireland, 2018; Houses of the Oireachtas Committee on the Future of Healthcare, 2017). A recent review by Irish researchers examined the literature on the integration of primary and hospital care to enhance chronic-disease management understandings for Ireland (Murtagh et al., 2021). The authors identified three specific interventions to enhance integration of care for chronic-disease patients: eHealth interventions, multidisciplinary teams, and education of healthcare professionals. Importantly, the authors state that an ineffective electronic integration process does not have a neutral effect but rather hinders integration of care (Murtagh et al., 2021). Other Irish research also identified integration and investment in HIS and EHRs as key for chronic obstructive pulmonary disease (COPD) patients (Boland et al., 2015; Ferrone et al., 2019). Therefore, ensuring that different ICT systems can communicate and be integrated with each other is required for an effective health management system in Ireland, and to enable Sláintecare proposals to be realised.

In addition to investment in additional ICT systems, improvements in the use of health informatics also require a reorientation of healthcare organisations around 
the production of data (Bossen et al., 2019). While this is often overlooked, it means that there are many new occupation groups within healthcare systems that are centred on data work and that current healthcare workers will need to further develop skills in health data management (Bossen et al., 2019). This has been recognised by many groups. A study by the Organisation for Economic Cooperation and Development (OECD) of HIS in OECD countries indicated that a digital transformation is currently being hampered by healthcare workers being 'illprepared' for such a change (Colombo et al., 2020). A review of the use of HIS for chronic illness showed that, while the benefits are clear, there are some negative aspects (Dorr et al., 2007). It found that healthcare workers emphasised usability as a clear need, as well as issues around time for training, staff anxiety about the technology, and clinicians being overwhelmed by updates and messages (Dorr et al., 2007).

\subsubsection{Electronic Health Records (EHRs)}

EHRs are a specific from of big data. They represent a more patient-specific data system, established as a central tenet of many health systems in international practice. EHRs are a digital record of a patient's interactions with different areas of the healthcare system. The OECD has identified two distinct approaches to developing an EHR system (Colombo et al., 2020):

- a 'one patient one record' approach whereby healthcare providers have access to one centrally stored system of records;

- a more disaggregated approach where different platforms and local systems are configured to exchange data to create a complete view of an individual's interactions with the healthcare system.

HIQA recently published a report on recommendations to support the successful implementation of a national electronic patient summary in Ireland. This will be an important stage that can ultimately lead to the development of a national EHR (HIQA, 2020). The report highlighted that, in countries such as Northern Ireland, the implementation of a national electronic patient summary (a precursor to a national EHR) built public trust in such data. It also provided important understanding for the later introduction of a national EHR (HIQA, 2020). Countries such as Australia, the US and UK have already made considerable progress in establishing an integrated EHR system (see next section). As we discuss in our review of the international systems later in this chapter, the benefits of having a universal EHR (where data can be linked across systems) in countries such as New Zealand, Denmark and the Netherlands (using the 'AORTA' IT infrastructure (HSE, 2013)) have given policymakers more power to quickly respond to the COVID-19 outbreak.

Figure 2.1, from Jensen et al. (2012), illustrates the infrastructure of a generic EHR system. It clearly shows that an EHR database acts as a central repository of a 
patient's health information, from a number of services, over time. The EHR database can then be used by clinicians and patients, at their points of care, to provide statistics to policymakers (an important but often underemphasised feature of EHRs), and as a database for research to inform clinical care.

\section{FIGURE 2.1 ELECTRONIC HEALTH RECORD INFRASTRUCTURE}

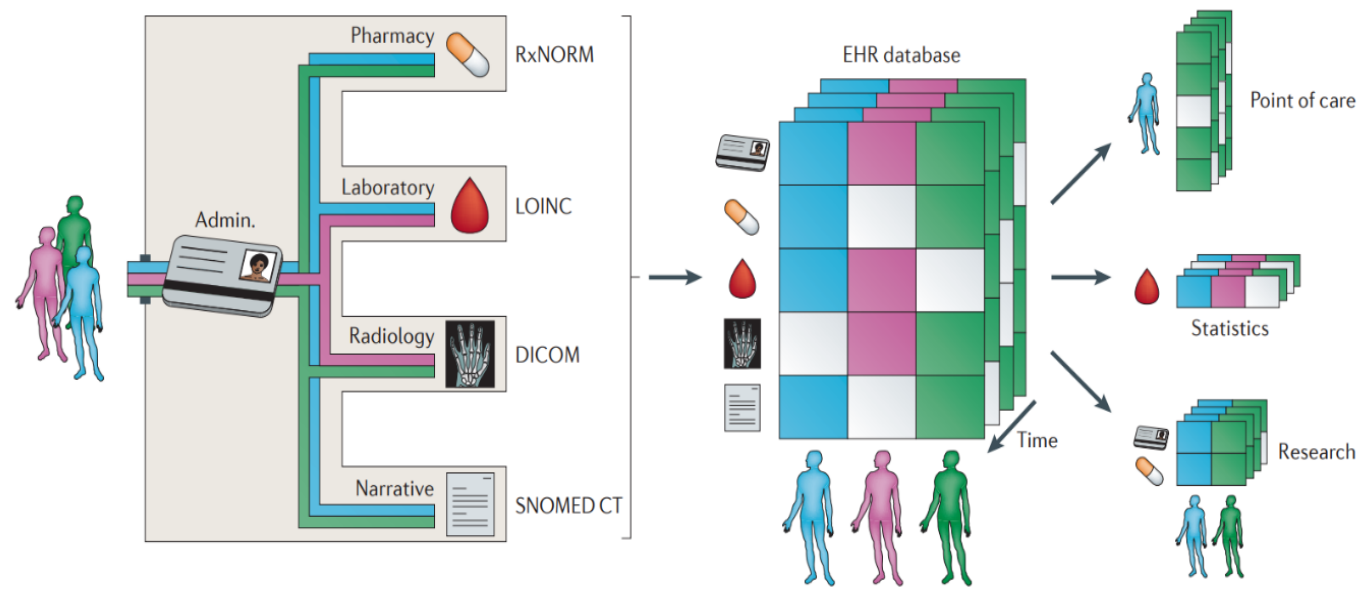

Source: Jensen et al., 2012.

Colombo et al. (2020) recommended that digital healthcare strategies aim to facilitate individuals accessing their own digital records, while noting that a lack of general health literacy may limit the benefits of this aspect.

\subsubsection{Cloud-based systems}

Cloud-based computing is a new, important health technology. It has been defined as 'a model for enabling ubiquitous, convenient, on-demand access to a shared pool of configurable computing resources' (Mell and Grance, 2011). Improved exchange of information in a healthcare system can be fostered by cloud computing and shared electronic platforms. The advent of cloud computing is a fundamental enabler of the use of high-end information systems and big-data analytics in healthcare (Aceto, Persico and Pescapé, 2020).

The cloud computing model of data infrastructure offers advantages including ondemand availability of large-scale computing resources, the reduction of up-front commitments by users required for establishing data systems, and payment for use on a short-term basis as needed (Kuo, 2011). Therefore, the establishment of a cloud-based EHR system would make the use of EHR data, as described in Figure 2.1, much more efficient and reduce barriers to the use of these data.

An overview of literature on the use of cloud computing in healthcare found that resource-intensive applications such as medical imagery, and applications based heavily on communications such as telehealth, are highly suited to the use of cloud computing (Griebel et al., 2015). Evidence from the literature also provides advice 
on how to support HIS and improve the adoption of EHRs (Griebel et al., 2015; Kuo, 2011). Challenges in incorporating cloud computing into healthcare systems have also been identified, including data safety and security, the transparency of thirdparty data handling, and a lack of experience in the use of new technologies (Griebel et al., 2015).

The use of data dashboards can assist in planning and decision-making tailored to local, regional and national contexts. However, Cresswell et al. (2021) highlight that the impact of these cloud applications has not yet been fully evaluated, and thus their effect on clinical outcomes remains unknown. Furthermore, issues concerning governance, security, data structures and data harmonisation underpinned by cloud-based providers may not have been adequately considered due to the hurried nature of implementation during the COVID-19 pandemic (Cresswell et al., 2021). These issues will be important to understand for the future implementation of cloud-based systems.

\subsection{INTERNATIONAL PRACTICE}

The previous section highlighted how HIS and data infrastructure are broadly applied in health systems. This section describes their use across international health systems. The HSE (HSE, 2013) and HIQA (HIQA, 2014) have undertaken similar exercises previously. Where appropriate, we also concentrate on how HIS have been used in various countries to address the challenges presented by COVID19 (not covered in previous reviews). To provide a broad review, we discuss HIS across healthcare systems that are organised differently (i.e. government-funded, funded by public insurance, funded by a combination of public and private insurance). We do not attempt to fully analyse all components of HIS across different systems. Rather, we focus on particular components that may be unique to specific healthcare systems, and that may be informative for developing HIS and health informatics in Ireland.

\subsubsection{Scotland}

Scotland offers a potential template as to how to improve HIS and eHealth in Ireland. Electronic prescribing (e-prescribing), an ICT-enabled administration system for chemotherapy, and an e-referral programme have been a feature of NHS Scotland for a number of years (HIQA, 2016). These eHealth initiatives are built around EHRs and the Community Health Index $(\mathrm{CHI})$, a unique identifier given to all individuals who interact with NHS Scotland, generally on registering with a GP. The use of the $\mathrm{CHI}$ is mandated across all NHS Scotland systems, and individuals accessing NHS services cannot opt out of the CHI system (Scottish Government, 2013).

The $\mathrm{CHI}$ is used to identify and link information on individual service users across different elements of the NHS Scotland system, and is also the primary source of 
demographic information for local health boards. The $\mathrm{CHI}$ can now follow the care of individuals from their birth records to their death records (NHS Scotland, 2021).

The data collected through the $\mathrm{CHI}$ can be used for research to expand knowledge and has been a clear goal of policymakers in Scotland. A 'National Safe Haven' ${ }^{1}$ has been developed to keep data safe and secure; researchers can access anonymised versions of the data for their research. NHS Scotland has outlined a vision for the continued use of these data for research to inform planning of services and better clinical care pathways (NHS Scotland, 2021).

\subsubsection{England}

Similar to Scotland, NHS England has embraced HIS, eHealth and expanding health data infrastructure across the system. Integral to the data infrastructure of NHS Digital (the national information and technology partner of the NHS) is the 'NHS Spine'. ${ }^{2}$ This central database joins over 28,000 IT systems across different providers and allows secure sharing of health information (NHS Digital, 2019). NHS England is currently transferring from a system that still incorporates paper-based records, while there is often a lack of integration of records collected across a myriad of datasets. There are also plans to redevelop the NHS Spine to allow it to become a cloud-based service. ${ }^{3}$ NHS Digital is planning to merge all data into a single data infrastructure in the coming years, and data will flow from providers directly to a data services platform (NHS Digital, 2018). This comprehensive EHR system plan has been reiterated as part of the NHS Long Term Plan (NHS England, 2020), and using EHR data and decision supports and AI to help clinicians within patient care is envisaged (NHS England, 2020). The emphasis on increased digitisation in the NHS is also seen in the commitment that by 2023/24 every patient in England will be able to access a digital first primary care offer. ${ }^{4} \mathrm{~A}$ digital data hub that would extract routinely collected data from GP records for use in clinical trials, and to enhance disease surveillance, has also been proposed (de Lusignan et al., 2020).

From a research perspective, administrative health records have been linked with longitudinal survey data to further expand the research that can be undertaken; the English Longitudinal Study of Ageing (ELSA) has been linked with Hospital Episode Statistics. ${ }^{5} \mathrm{~A}$ new analytics platform called OpenSAFELY was developed to deliver rapid results on COVID-19 patients. A pragmatic approach was adopted, where analysts can conduct large-scale computation of near real-time pseudonymised patient records in data centres and secure the cloud environments

\footnotetext{
${ }^{1}$ https://www.isdscotland.org/products-and-services/edris/use-of-the-national-safe-haven/

2 https://digital.nhs.uk/services/spine

3 https://www.nao.org.uk/wp-content/uploads/2019/05/Digital-transformation-in-the-NHS.pdf

4 https://www.england.nhs.uk/wp-content/uploads/2020/01/online-consultations-implementation-toolkit-v1.1updated.pdf

${ }^{5}$ https://www.elsa-project.ac.uk/linking-your-data
} 
of the software companies where EHRs are held. Research carried out through this platform has been undertaken to better understand COVID-19 patients, and inform clinical pathways of care for patients (Williamson et al., 2020).

\subsubsection{Canada}

Canada does not have an NHS-type healthcare system, but rather a decentralised, universal-coverage but publicly funded health system, known as Canadian Medicare. Administration and funding are the responsibility of Canada's 13 provinces and territories. In general, all residents receive medically necessary hospital and GP services free at the point of use (Allin et al., 2020), but there are differences in, for example, how eHealth has been adopted across regions.

EHR rollout is not as developed in Canada as other countries. The incompatibility of different EHR systems across the decentralised Canadian health system has contributed to this. In 2001, to help alleviate this issue, a non-profit and federally funded organisation, Canada Health Infoway, was created to develop a national data infrastructure (Canada Health Infoway, 2016; Chang and Gupta, 2015), and now approximately 73 per cent of GPs have access to EHR data assets (Canada Health Infoway, 2020). Canada's decentralised healthcare system has also led to wide regional variation in the adoption of electronic records by physicians (Chang and Gupta, 2015), and variation in the adoption of integrated IT systems across hospitals (Lau et al., 2011).

While the fragmentation in the Canadian system cannot be cited as the main impediment to an integrated HIS and EHR system, the Canadian experience does point to the benefits of a HIS within more decentralised healthcare systems where there is variation in the adoption of EHRs and eHealth solutions across a country.

\subsubsection{Denmark}

Denmark is acknowledged as a world leader in HIS and eHealth. Every Danish citizen has a centralised identifier that tracks every contact with the healthcare system (Chang and Gupta, 2015), including e-prescribing, primary care notification by hospitals and Computerised Physician Order Entry Systems (Deloitte \& Touche, 2015). Denmark's health data infrastructure has enabled world-leading health service and epidemiology research. Its extensive network of medical databases, which capture information from birth, with high-quality data routinely collected on patients thereafter, gives researchers the ability to examine many important questions. Some have even argued that the data available allows for 'unlimited possibilities for epidemiological research' (Jefferies et al., 2020).

While health data in Denmark is extensive, features of the health system reduce its capabilities. Denmark has a decentralised healthcare system where regions and municipalities play a key role in healthcare planning and providing public 
healthcare services (OECD, 2013). This means there has traditionally been a limited national data infrastructure for the health data available. A government-financed cooperative, MedCom, is working towards achieving convergence across disparate local systems by setting national data standards (Chang and Gupta, 2015). In addition, a national portal, Sundhed, collects information on prescription history, test results and allergies from hospitals and GPs, and makes these data available to all clinicians (Deloitte \& Touche, 2015). This is further evidence that, where care is decentralised to regional authorities, a centralised infrastructure component (similar to the $\mathrm{CHI}$ in Scotland) is required to make full use of health data.

\subsubsection{Estonia}

Estonia is at the forefront of HIS and eHealth worldwide. It was an early adopter of integrated HIS and, in 2008, a nationwide eHealth system was established (Habicht et al., 2018). Each person in Estonia has an online EHR (an e-Health record) that can be accessed by clinicians and individuals (e-Estonia, 2021). Records are protected using a Keyless Signature Infrastructure, a blockchain technology. The eHealth record is incorporated across healthcare systems.

One key aspect of the Estonian system is the ability of individuals to interact with their data. Through this system, they can update their details, undertake administrative processes such as obtaining a medical certificate, see who has access to their data, and deny access to their data (Colombo et al., 2020; Habicht et al., 2018). Despite the clear importance of the system in Estonia, as in other countries, decentralised information systems across providers and lack of integration of the system to inform clinical care pathways have been highlighted (Habicht et al., 2018).

\subsubsection{The Netherlands}

The Netherlands has been characterised as 'one of the EU's leaders' in the area of health informatics. A National IT Institute for Healthcare was established in 2002 to facilitate the exchange of data between healthcare providers, although plans for the national rollout of an EHR system were shelved in 2010 due to issues around security, data protection and clinical acceptance (HIQA, 2016). Regional EHR systems are being developed, supported by a national standardised data infrastructure know as AORTA, where GP records are stored. Individuals are identified in the AORTA infrastructure using a citizen service number, the BSN number, which is also used by Dutch citizens when dealing with other services such as benefits agencies and schools (Spronck, 2008).

An electronic locum record system has been successfully piloted in the Twente region in the Netherlands; it allows locum GPs such as out-of-hours practitioners to access a summary of a patient's records from their regular GP (HIQA, 2016). 


\subsubsection{New Zealand}

Having been regarded as a world leader in healthcare ICT since the 1980s, New Zealand has built up considerable experience in linking local systems to national datasets and in integrating different data platforms. It has a well-established registry for tracking patients, the National Health Index (NHI). An NHI number is assigned to each individual who receives healthcare in the country, and the system holds the demographic data of patients (New Zealand Ministry of Health, 2018). This provides a foundation for a developing EHR system (Deloitte \& Touche, 2015).

Health authorities commissioned a review of New Zealand's EHR system strategy. This noted that the overall system landscape remained complex, as the use of 'virtual' EHRs, where data is assembled from various systems on demand, was preferred over 'single' or 'physical' EHRs where data is stored in a central repository (Deloitte \& Touche, 2015). These recommendations have resulted in the development of the National Health Information Platform (NHIP) (New Zealand Ministry of Health, 2019). This platform enables healthcare providers to access a summary record for patients based on information collected across other systems (e.g. GP systems) using patients' NHI number. Information on demographics, diagnoses, hospital visits, test results, prescribed medications, known allergies, community care, e-referrals and discharge summaries, etc can be seen even in the absence of a universal EHR (HIQA, 2016). This highlights that a different approach to the universal EHR is possible, but it requires the ability to follow individuals across the health system (which the NHI number allows), and different systems to be compatible and be able to communicate with one another.

\subsubsection{United States}

It is difficult to examine healthcare systems across the United States (US) due to the varied nature of access and provision across states, and between public and private healthcare within states. However, healthcare systems in the US have been characterised by a very high level of use of health informatics, and a high level of EHR penetration (O'Reilly-Shah et al., 2020). Over 95 per cent of hospitals in the US are estimated to use EHR systems (Sittig and Singh, 2020). While there is now greater parity, the adoption of health information technology such as EHR systems was previously found to vary considerably by region in the US, with many local health departments, particularly in smaller, more rural jurisdictions, lacking the capacity to adopt health informatics (Shah et al., 2016).

While no nationwide data infrastructure exists in the US healthcare system, Sittig and Singh (2020) suggested that the widespread use of EHRs in individual hospital organisations offers an opportunity to develop such an infrastructure based on a network of interconnected 'health nodes', with each individual organisation's EHR system acting as a node. However, significant barriers exist to developing a nationwide infrastructure; for example, the lack of a national unique patient 
identifier (O'Reilly-Shah et al., 2020; Sittig and Singh, 2020).

Some systems or providers of care in the US are consistently at the forefront in the development of HIS in the US. Kaiser Permanente, the largest non-profit private healthcare provider in the US, operates on the US west coast as well as in Colorado, Georgia, Hawaii, Maryland, Virginia, and the District of Columbia. In 2002, Kaiser Permanente launched its HealthConnect system, a sophisticated EHR infrastructure integrated across all nationwide healthcare settings within the organisation. This represents a single-vendor EHR model across inpatient, outpatient, community, diagnostic support, pharmacy and primary care settings (Deloitte \& Touche, 2015).

Despite the clear fragmentation of healthcare in the US, there are some panAmerican examples of integration of HIS and health data for specific populations. The Surveillance, Epidemiology and End Results (SEER) registry is a series of cancer registries that collect information on people living with cancer. This database has been linked with Medicare healthcare services use and claims data, SEERMedicare. ${ }^{6}$ This database has offered the opportunity to undertake a plethora of research on cancer care in the US.

Outside of acute healthcare, health informatics are increasingly used in the areas of post-acute (rehabilitation), home health care, and residential care. Some of this is due in part to recent federal mandates. All Medicaid or Medicare-certified nursing homes are federally mandated to contribute to a minimum dataset on the health status of residents. ${ }^{7}$ The dataset captures information on nursing home residents' health, comorbidities, treatments (e.g. chemotherapy) and therapies (e.g. occupational therapy).

\subsection{HEALTH INFORMATION SYSTEMS AND THE RESPONSE TO COVID-19}

The COVID-19 pandemic has been a catalyst for the rapid adoption of HIS improvements and eHealth. Since the onset of the pandemic, health informatics has been highlighted as having a crucial role in the response of healthcare systems to COVID-19 (Bakken, 2021, 2020). This section outlines how data infrastructures can support a healthcare system's response to a public emergency such as COVID19. It highlights the data requirements and coordination between different datasets and systems required for COVID-19 testing, as well as contact tracing. It also provides some evidence that has emerged on the leveraging of data systems as part of the response to COVID-19 in international practice.

\footnotetext{
${ }^{6}$ https://healthcaredelivery.cancer.gov/seermedicare/medicare/table.html

${ }^{7}$ https://healthcaredelivery.cancer.gov/seermedicare/medicare/mds.html
} 


\subsubsection{Healthcare system response to public health emergencies}

COVID-19 tracing

In responding to public health emergencies, a developed healthcare system data infrastructure underpinned by effective governance can provide substantial benefits. Such systems can more accurately estimate a real-time burden of disease and demand for resources, allow for the collection of data at local or regional level, and provide a foundation for public health-based surveillance strategies (Sittig and Singh, 2020). In particular, the collection of accurate and reliable real-time data and the rapid and accurate sharing of this information between healthcare organisations and public health agencies are integral to an effective response to a public health emergency (Sittig and Singh, 2020; Holmgren et al., 2020). Several metrics have been identified as critical for reporting as part of managing a public health emergency, including hospital capacity, healthcare staffing needs, healthcare supply chains, and data on infections, including demographics and health outcomes (Subbian et al., 2021). Clinical decision-making can also be supported by monitoring longitudinal and real-time patient data, which can be facilitated by an EHR system.

In addition to data sharing between healthcare settings and public health agencies at various levels of administration, public information resources that provide realtime data for tracking infection outbreaks are important (Madurai Elavarasan and Pugazhendhi, 2020; Wissel et al., 2020). Adherence to public health guidelines or regulations may be affected by individuals' risk perception. Countering any spread of false information with up-to-date government information has been highlighted as important (Madurai Elavarasan and Pugazhendhi, 2020). The WHO has emphasised the importance of testing individuals for infection as part of a pandemic response (WHO, 2020). A central goal is to control the spread of a virus by preventing transmission and eliminating any local outbreaks. Key to achieving this goal is a strategy of testing, contact tracing and the self-isolation of any positive cases (Salath et al., 2020).

For a number of reasons, such as its location, island status and effective isolation and quarantine as a country, New Zealand was able to reduce the impact of COVID19. However, the well-established patient-registry, and its ability to engage with other parts of the system (EpiSurv is New Zealand's digital notifiable disease information system), may also have been of help, as discussed by New Zealand's Director General of Health in early April 2020. 
"The tremendous advantage for New Zealand is having the National Health Index."

"By moving our contact tracing on to that electronic data base and being able to connect through the NHI and our data base of cases kept by ESR on EpiSurv, we can link by NHI to laboratory data, clinical data and clinical outcomes and build up a really good picture."

"This is the week that we will be able to pull all that information and data together from databases using that NHI linkage and it will be very helpful in being able to describe the picture in New Zealand from an epidemiological perspective, by identifying populations at higher risk and geographical areas where we need to do more testing."

Director General of Health, New Zealand ( $7^{\text {th }}$ April 2020)

A key barrier to COVID-19 surveillance and monitoring in many countries has been poor public health IT systems and data infrastructure. In the US, to facilitate the monitoring of the pandemic, hospitals are required to electronically send health information, including test results and syndromic surveillance data, to local, state or federal public health agencies. However, technical and administrative barriers impede the flow of such information, leading to inconsistent reporting and information gaps (Holmgren et al., 2020). The lack of capacity in public health agencies to receive the electronic data sent to them was the most prevalent barrier (Holmgren et al., 2020). The study also noted that hospitals may report to both local and state public health agencies, which may have different capabilities in relation to handling data. This resulted in academic and newsgroup-based data sources being relied on in the absence of a uniform government standard for tracing outbreaks of COVID-19 (Dixon et al., 2021; Wissel et al., 2020).

The long-term residential care sector (i.e. nursing homes) has borne the brunt of COVID-19. However, across countries, policymakers struggled to understand the true extent of COVID-19 outbreaks and deaths in nursing homes. Even in England, which has a strong health data infrastructure, there is little data available on the long-term residential care sector. This may be because most care-home providers are privately owned, unlike NHS facilities in other areas of the health system. A lack of standardisation across different bodies collecting information on these providers contributes to a lack of data on basic information, such as the number of residents or hospital admissions (Hanratty et al., 2020). Hanratty et al. (2020) suggest that longitudinal data on COVID-19 infections and deaths in care homes would have allowed real-time monitoring from the beginning of the pandemic, offering the capacity for early virus detection as well as evidence on the natural 
course of COVID-19 in care homes to enable designing targeted interventions (Hanratty et al., 2020). At a local level, some novel approaches were taken. In Manchester, a care data tracker was established to allow care homes to provide real-time information about residents to GPs and hospitals, and a capacity tracking app monitored care home staffing and occupancy all over England (Hanratty et al., 2020).

\section{COVID-19 testing}

The process of testing during a pandemic typically involves multiple systems and is inherently centred on data (Lenert and McSwain, 2020). An individual suspected of infection may initially be screened by a primary care or hospital clinician through telehealth channels. If referred for a test at this initial stage, the individual may then have a swab test sample collected at a drive-through site (Ton et al., 2020), most likely run by a separate organisation. Their sample will be sent for testing in a clinical laboratory with capacity, which may be another separate entity. A followup to this test will then be conducted to inform the individual, a process which may be administered through primary care or through a separate case-management institution. Depending on the result of this test and other factors, the individual may then require hospitalisation in an acute healthcare setting that has sufficient capacity. In the case of a positive test, a contact tracing process should also commence to identify other potentially infected individuals. Overall, this often represents a complex, ad hoc system consisting of several different organisations and data collection systems (Lenert and McSwain, 2020). In the case of COVID-19, the rapid identification and containment of any positive cases is particularly important due to the potential for asymptomatic spread, coupled with a high mortality rate among vulnerable groups (Grange et al., 2020). The management of data across disparate systems can play a role in determining the speed of the process.

Clinical laboratories may employ a laboratory information system (LIS) to support this testing process. Weemaes et al. (2020) outlined three phases of the testing process that can be supported by a LIS: (a) a pre-laboratory phase, including tasks such as test ordering, sample packaging and shipping, (b) a pre-analytical phase, encompassing sample registration, tracking and test prioritisation, and (c) a postanalytical phase, involving automated reporting and data-driven policy decisionmaking. The UW Medicine healthcare system in the US has acted as a major regional referral laboratory for COVID-19 testing. UW Medicine interfaced a LIS with its EHR system to allow for tests to be ordered through an individual's EHR (Weemaes et al., 2020). The LIS was also linked with external public health systems for automated reporting of cases. A real-time dashboard of critical metrics on testing and hospital capacity, with information used by command centres to project demand relating to COVID-19, was subsequently created from these data (Grange et al., 2020). 
The Belgian National Reference Center, in the early stages of the pandemic, was the only COVID-19 testing centre in Belgium. Major bottlenecks formed, stemming from an ordering system that involved the use of paper forms and the manual input of data into the LIS, including missing information on forms and difficulties in rapidly changing test ordering behaviour to reflect evolving criteria for testing (Weemaes et al., 2020). In response, a computerised order system was developed to replace paper forms for hospital testing, so that tests could be ordered directly from an individual's EHR. The EHR system was further linked with the LIS to allow for the automatic retrieval of demographic information on patients, and for realtime COVID-19 status to be added to the main page of each patient's EHR. In the case of tests referred from other laboratories in Belgium, a tool was developed within the LIS to support administrative personnel in registering information from paper forms, and automated reporting was established through a database including the contact details of other laboratories (Weemaes et al., 2020).

EU states cooperated on the use of smartphone apps to support the contact tracing process by testing the interoperability of various member states' contact tracing apps (EC, 2020b; eHealth Network, 2020). This approach to contact tracing is an example of a voluntary 'Trace, Test and Treat' approach, compared with a 'Trace and Track' method employed by other countries such as Taiwan. The more covert Trace and Track approach, involving the automated and involuntary tracking of members of the public, is regarded as being effective in managing infection rates but at the cost of being highly intrusive, raising considerable ethical and privacy concerns (Subbian et al., 2021).

In addition to contact tracing among the general public, some contact tracing occurs within healthcare settings such as hospitals. In Singapore, an algorithm was developed to integrate data from separate data systems within a hospital to determine the journey of patients through the hospital, and to identify contacts within the hospital. This combined use of existing data infrastructures was found to significantly reduce time spent by healthcare staff on within-hospital contact tracing (Venkataraman et al., 2020).

\section{COVID-19 patient care}

Telemedicine has been a key feature of health systems' response to ensuring people can access care in a safe manner during Covid-19. In many countries, including Ireland, telemedicine is a key form of accessing primary and hospital care (Banks et al., 2021; Greenhalgh et al., 2020; Homeniuk and Collins, 2021). In some systems, telemedicine technology has been linked to EHR systems to allow the monitoring of patients through a continuum of services (Ford et al., 2020). Alongside telehealth initiatives, the Medical University of South Carolina in the US introduced a population management tool for COVID-19 patients (Ford et al., 2020). It extended its EHR system to allow low-risk patients to self-report outcome 
measures from home, developed a smartphone app and patient sensors for COVID19 patients that passed information to each patient's EHR, and applied Al methods to clinical record data to predict when virtual care patients would eventually test positive for COVID-19, for the purposes of priority testing (Ford et al., 2020). In San Francisco, a digital self-triage and self-scheduling tool for COVID-19 testing was established and integrated into an existing EHR system, decreasing triage time for patients with a less severe illness, and preventing unnecessary triage phone calls or in-person visits (Judson et al., 2020). Many of these initiatives built on existing systems; e.g., remote patient monitoring was already in place for conditions such as diabetes, hypertension and asthma in San Francisco (Ford et al., 2020).

Reeves et al. (2020) highlighted the EHR as an integral system in supporting healthcare responses to COVID-19. As the world's understanding of COVID-19 has evolved, clinical practice has adapted accordingly. Data infrastructures such as EHR systems have been employed to rapidly communicate changes in patient care to clinicians across healthcare systems (Lin et al., 2020). In the US, existing EHR systems have been developed to include guidance on patient screening and testing, to facilitate the ordering of tests and validate clinical triage workflows (Subash et al., 2020). In NHS England, the OpenSAFELY analytics platform delivers rapid results on COVID-19 patients, using analyses of EHRs. In China, clinical information systems including EHRs have supported the healthcare system's response to COVID-19. This has revealed the importance of such systems being capable of rapid deployment and flexible response to changing needs in an emergency, as well as being capable of information exchange with other systems (Ye et al., 2020).

\section{COVID-19 Vaccinations}

Subject to the existence or availability of suitable vaccines, immunisation strategies are also central to a health system's approach to tackling a public health emergency. This is another area where HIS and data infrastructures can play a supporting role, particularly when the speed of a large-scale immunisation programme is crucial. An immunisation programme may involve multiple organisations. For example, in a public health emergency (as has occurred with COVID-19), vaccinations may be offered simultaneously in hospital hubs, in largescale temporary vaccination centres, and in primary care clinics. In addition, certain population cohorts may be specifically targeted for immunisation ahead of others in the case of limited vaccine supply. The use of population databases recording vaccination doses administered by various healthcare providers, known as immunisation information systems (IIS), has previously been found to support immunisation programmes (Community Preventive Services Task Force, 2015; Martin et al., 2015; Urquhart et al., 2007). These systems can help inform vaccine allocation, facilitate vaccine ordering, monitor vaccine inventories, measure effectiveness and evaluate public health responses (Community Preventive Services Task Force, 2015). 
The first COVID-19 vaccination programmes commenced in December 2020 in the UK, the US, Canada, Russia and across the EU. In the UK, as with existing national immunisation programmes (e.g. for seasonal influenza), the COVID-19 vaccination programme is supported by EHR systems. Data extracted from GP data systems, linked to clinical information on patients, is aggregated to allow monitoring of vaccine coverage among different cohorts of the population. In addition, an IIS known as the National Immunisation Management System has been developed to provide a central register of vaccines delivered across a range of healthcare settings (UK Department of Health and Social Care, 2021).

\section{Ethical concerns}

While the sharing and analysis of high-quality, patient-level data is considered an important aspect of responding to a public health emergency, there are ethical and legal implications of developing and using large datasets in healthcare (Raisaro et al., 2020; Subbian et al., 2021). A trade-off between the usefulness of healthcare data and the level of data protection has been identified (Raisaro et al., 2020). It has also been argued that concerns in relation to privacy and ethics have led to a reluctance on the part of healthcare organisations to enter into data-sharing agreements, and that this has hampered efforts to increase the interoperability of healthcare data (O'Reilly-Shah et al., 2020).

\subsection{CONCLUSIONS}

HIS, health informatics and health data infrastructures are playing an everincreasing role in healthcare. The responses of healthcare systems to COVID-19 have further illustrated this. The inadequacy of healthcare system data infrastructures - for example, in relation to data collection and sharing - has been clearly highlighted by the pandemic. More positively, there have been many examples in international practice of rapidly deployed innovations in health informatics in response to COVID-19, many of which have built on existing data infrastructures. Healthcare data infrastructures have supported many areas including disease monitoring, patient care, testing and tracing, and immunisation programmes during the pandemic.

One recurring theme in the academic literature and international practice is the integral role an EHR system can play in healthcare systems. Another common theme in international practice is the benefits of having a unique patient identifier and a national EHR. Countries such as New Zealand, Denmark and the Netherlands have such infrastructures in place, allowing them to identify and link information on individual service users across different service elements over time.

The interoperability of various healthcare data systems is regarded as important to maximise the benefits of health informatics. In countries such as the US and Canada, regional variation in the evolution of healthcare data infrastructures over 
time has limited the linking of different EHR systems, for example. It is important that such benefits are always balanced with ethical and privacy considerations, particularly given the highly sensitive nature of healthcare data. NHS Spine in England is an example of a national centralised data infrastructure being developed for linking patient information from across healthcare settings. Cross-border initiatives on healthcare system data infrastructure are in progress in the EU, with the development of an eHealth Digital Service Infrastructure that aims to include cross-border sharing of summary care records. 


\section{CURRENT HEALTH DATA LANDSCAPE IN IRELAND}

\subsection{INTRODUCTION}

This chapter provides an overview of the current health data and information infrastructure in Ireland. To identify areas that have the potential for policy intervention and improvement, we discuss some key limitations of the healthcare system data infrastructure. Recent changes and advancements are also highlighted.

\subsection{HEALTHCARE SYSTEM DATA INFRASTRUCTURE IN IRELAND}

\subsubsection{Healthcare system}

To provide context in which to frame a discussion of the healthcare system data infrastructure in Ireland, we provide a brief overview of the healthcare system itself. A number of recent ESRI publications discuss some of the specific parts of the system in greater detail (Keane et al., 2021; Nolan et al., 2014; Smith et al., 2019; Walsh et al., 2019a; Walsh et al., 2019b; Wren and Fitzpatrick, 2020; Wren and Connolly, 2017; Wren et al., 2017).

The healthcare system in Ireland differs in several ways from that in most other European countries. While 78 per cent of healthcare expenditure is governmentfunded, not everyone is entitled to free public healthcare (Wren et al., 2015). Patients with a Medical Card (or GP Visit Card) can access public healthcare (or GP care) for free. Patients who do not have a Medical Card must pay out of pocket for care (i.e. $€ 50+$ per GP visit (Connolly et al., 2018; Walsh et al., 2019a)). The private sector plays a significant role in the Irish healthcare system both in terms of provision of services and through private health insurance.

In recent decades, a two-tiered healthcare system has developed in Ireland along the lines of public and private care. The absence of universal access to free primary and hospital care has resulted in many people purchasing private health insurance. Long waiting lists for publicly provided outpatient and elective care in public hospitals in Ireland (Brick and Connolly, 2021) is given as the main reason for purchasing private health insurance (Harmon and Nolan, 2001; Kapur, 2019; MillwardBrown, 2016). The fragmented nature of healthcare financing in Ireland constrains the development of a HIS spanning the whole system.

\subsubsection{Health information systems in Ireland}

In this section we provide an overview of the policy developments and key features of the HIS landscape in Ireland. The development of health data infrastructures and the use of eHealth as part of Ireland's health service offering have been recognised in domestic legislation and policymaking. In chronological order, the most 
important measures are:

- Health Act 2007: the establishment of the Health Information and Quality Authority (HIQA), an independent authority charged with regulation, data and information standards for health and social care providers in Ireland. HIQA has provided invaluable expert opinion on various elements of HIS and eHealth in Ireland, including having an active role in informing policymakers during COVID-19. HIQA also has extensive involvement in providing information on HIS and the introduction of IHIs.

- eHealth Strategy for Ireland 2013: this strategy laid out how to suitably and effectively introduce and use eHealth and health data in Ireland. A new organisational role was provided to a new authority called eHealth Ireland, which sits within the HSE. eHealth Ireland has been at the forefront in the development of various initiatives in the health service, as well as working with academic and industry colleagues on various eHealth initiatives. The Office of the Chief Information Officer (CIO) delivers ICT services and support throughout the HSE. Most recently, eHealth Ireland has been involved in the following initiatives in HIS and eHealth:

○ IHI Rollout

- National Waiting List Management System

- Health Pathways

- ePharmacy / ePrescribing

- Residential Care Management System and Home Support System

- Video Conferencing / Remote Consultation

- Electronic Discharge System

- Health Performance and Visualisation Platform

- Integrated Information Services Supporting Recovery

- Shared Care Record

- Community Hub Management System

- Clinical Notes

- Lighthouse projects (e.g. PISCES (Providing Individualised Services and Care in Epilepsy), a Lighthouse Project with a number of partners including HSE, eHealth Ireland, Epilepsy Ireland, the Royal College of Surgeons in Ireland (RCSI) and Beaumont Hospital, Dublin

- Health Identifiers Act 2014: this Act legislated for the introduction of the unique Individual Health Identifier (IHI). It provides the legal basis for the establishment of the National Register of Individual Health Identifiers and the National Register of Health Services Provider Identifiers (HIQA, 2015b).

- Knowledge and Information Strategy: Delivering the Benefits of eHealth in Ireland 2015 - this strategy built on the previous 2013 eHealth strategy 
and outlined how integrated information and enabling technology will support the delivery of innovative healthcare in the Irish healthcare system (HSE, 2015).

- National Electronic Health Record: Strategic Business Case 2016 - this document outlined a Strategic Business Case for the investment of up to $€ 875$ million to deliver a national EHR across the Irish healthcare system (HSE, 2016).

- PA Consulting Capacity Review 2018: this review provided evidence on capacity requirements across the health and social care system. It also stated the need to 'invest in ICT infrastructure and, in particular, eHealth: eHealth and ICT were generally viewed as critical enablers to developing a more efficient and integrated health system. This would also include improved data collection to better allow planning for population health needs' (PA Consulting, 2018).

- Sláintecare Implementation Strategy 2018: Strategic Action 10 of the Sláintecare Implementation Plan seeks to 'put in place a modern eHealth infrastructure and improve data, research and evaluation capabilities' (Government of Ireland, 2018). In particular the Implementation Plan concentrated on ICT.

"ICT has the potential to be the biggest and most effective driver of change and improvement for better patient outcomes across the health system. In the future, a coherent suite of eHealth solutions will underpin and support our overall vision for integrated, patient-centred care, population health planning and more effective and safe delivery of health services. Patients and health professionals will have ready access to clinical records and administrative information, which will enable better decisions to be made."

\section{Sláintecare Implementation Plan}

Source: Government of Ireland, 2018

It is difficult to compare spending on HIS and health ICT across countries, but evidence points to Ireland consistently spending less of its health budget on HIS and ICT than its European peers. The 2013 eHealth strategy stated that, while many countries in the EU spent 2-3 per cent of their total healthcare budget on HIS and ICT, only 0.85 per cent of the healthcare budget in Ireland was spent on these services (HSE, 2013). There has been increased funding on eHealth and health data infrastructures in recent years. In 2018, the European Investment Bank provided a loan of $€ 225$ million for the progression of eHealth and the digitisation of the Irish 
healthcare system. ${ }^{8}$ Since the establishment of eHealth Ireland, the HSE has increased funding for HIS structures and ICT. Table 3.1 shows that, in 2017, the HSE capital budget for eHealth and ICT was $€ 55$ million. By 2020, this had risen to $€ 95$ million. As a consequence of COVID-19, the National Service Plan 2021 states that the eHealth and ICT Capital budget for 2021 was $€ 120$ million. Of this $€ 120$ million, $€ 41.7$ million was allocated to new projects, while €53.3 million was for capital already allocated to national programmes, solution programmes and technology. In addition, $€ 25$ million in funding was provided for eHealth \& ICT needs specifically associated with COVID-19. Of this $€ 25$ million, $€ 4.4$ million was allocated to cloud services infrastructure and storage, €3.7 million was allocated for Microsoft Teams deployed across the organisation (via Health|rl), and $€ 3.4$ million was set aside for technology refresh (e.g. progress device refresh within Microsoft Windows 10).

In addition to eHealth and ICT capital budgets, the National Service Plan 2021 provides details on current eHealth expenditure, with this funding assigned to the Office of the $\mathrm{CIO}$; 32.6 million is allocated to this budget. As the total HSE budget in 2021 will be $€ 20.6$ billion, this means that total eHealth and ICT spending still equates to less than 0.8 per cent of the budget, similar to the relative spend prior to the establishment of the eHealth Strategy.

TABLE 3.1

HSE EHEALTH AND ICT BUDGETS: 2017-2021

\begin{tabular}{|c|c|c|c|c|c|}
\hline & 2017 & 2018 & 2019 & 2020 & 2021 \\
\hline eHealth \& ICT & $€ 55 \mathrm{~m}$ & $€ 60 \mathrm{~m}$ & $€ 85 \mathrm{~m}$ & $€ 95 \mathrm{~m}$ & $€ 41.7 \mathrm{~m}$ \\
\hline Ongoing eHealth Programs ${ }^{a}$ & & & & & $€ 53.3 \mathrm{~m}$ \\
\hline eHealth \& ICT COVID-19 Capital Budget & & & & & $€ 25 \mathrm{~m}$ \\
\hline Total eHealth \& ICT - Capital Budget & $€ 55 \mathrm{~m}$ & $€ 60 \mathrm{~m}$ & $€ 85 \mathrm{~m}$ & $€ 95 \mathrm{~m}$ & $€ 120 \mathrm{~m}$ \\
\hline Office of $\mathrm{ClO}$ and Business Budget - Current Budget & & & & & $€ 32.6 \mathrm{~m}$ \\
\hline
\end{tabular}

Source: $\quad$ HSE National Service Plans 2017-2021.

Note: Due to the COVID-19 pandemic, the 2021 eHealth and ICT Capital Budget was split into additional categories including Ongoing eHealth Programmes, non-COVID-19 and COVID-19 Capital Budgets. Details on a current expenditure budget for the Office of Chief Information Officer and related business were also included in the National Service Plan 2021

a Capital allocated for National Programmes, Other Solution Programmes, Other Technology

Table 3.1 highlights the increase in expenditure on eHealth and ICT by the HSE. To progress eHealth in Ireland, continued and increased expenditure on these services will be required.

\subsubsection{Individual Health Identifier}

A key impediment to having a modern HIS and health data infrastructure in Ireland has been the lack of an individual health identifier. In 2009, HIQA published Recommendations for a Unique Health Identifier for Individuals in Ireland,

\footnotetext{
${ }^{8}$ https://www.ehealthireland.ie/news-media/news-archive/2018/eib-to-provide-\%E2\%82\%AC225m-loan-tosupport-rollout-of-ehealth.html
} 
concluding that IHIs would deliver tangible benefits in the areas of patient safety, quality of care, healthcare efficiency, confidentiality, epidemiology, and costeffectiveness (HIQA, 2009). The IHI was legislated for in the Health Identifiers Act $2014 .{ }^{9}$ This stated that the IHI would capture basic demographic information such as name, date and place of birth, gender, nationality, address, and date of death. The $\mathrm{IHI}$ can be used to identify an individual at the point at which they are using health and social care services. Unlike EHRs, the IHI will not store medical or clinical information; its key purpose is to aid communication across health service providers, and it is intended that health services providers will use an individual's IHI when communicating about that patient's care (HIQA, 2015a).

Despite being legislated for in 2014, the IHI has not yet been fully rolled out. But in recent years, an IHI was piloted and rolled out across a number of specific services. The IHI National Register has been implemented into the electronic referrals (eReferrals) service, the National Epilepsy Electronic Patient Record System, and the National Cervical Check programme. Importantly, a direct interface has been developed to allow for all four GP management systems (SocratesGP, HelixPM, HealthOne, and CompleteGP) to identify IHIs in real time. This is intended to ensure that all those who receive the COVID-19 vaccine are fully traceable. ${ }^{10} \mathrm{The} \mathrm{IHI}$ is also being used in the rollout of the vaccination programme. ${ }^{11}$

${ }^{9}$ http://www.irishstatutebook.ie/eli/2014/act/15/

${ }^{10}$ https://assets.gov.ie/108852/47f46ced-3f0d-4ff7-bac7-53a3d17923eb.pdf

11 https://www.hse.ie/eng/gdpr/data-protection-covid-19/data-protection-covid-19-vaccine-information-system.html 
"Integration of the individual health identifier, IHI, is critical to enable the HSE to safely administer the (Covid-19) vaccine. IHI integration is now live on the system."

"Progress to date includes integration of the system to the HSE service directory entries for more than 2,500 facilities including healthcare sites and new clinic locations. IHI integration is available, enabling access to real-time GP tables, professional ID validation and Eircode validation. The teams are working towards integration with GP systems to receive vaccine records."

- David Walsh, National Director, Community Operations of the HSE (29 January 2021)

"We are also very keen to make full use of the individual health identifier, IHI, and that, when we are registering people, we are assigning their IHI into the vaccination system to ensure we can uniquely track and trace them all the way through. It is a very good use of the IHI in this instance."

- Fran Thompson, Chief Information Officer of the HSE and CEO of eHealth Ireland $\left(29^{\text {th }}\right.$ January 2021)

Source: $\quad$ https://www.kildarestreet.com/committees/?id=2021-01-29a.363

\subsubsection{Electronic Health Records}

There is no universal EHR in Ireland. Analysis using the Health Care Quality Indicators (HCQI) Survey of Electronic Health Record System Development and Use, 2016, found that Ireland ranked the lowest of 30 OECD countries in technical and operational readiness for an EHR system (Oderkirk, 2017). The HSE's 2015 Knowledge and Information Strategy built on the eHealth Strategy for Ireland and outlined future required healthcare system capabilities, including the digital collection and use of data to support clinical and care capabilities, an EHR system and the integration of information across healthcare settings (HSE, 2015). The 2018 Sláintecare Implementation Strategy also identified an EHR as a priority among other ICT initiatives (Department of Health, 2018).

In Ireland, while no national EHR currently exists, there are a number of EHRs for specific populations or systems. The Maternal and Newborn Clinical Management System (MN-CMS) project has implemented an EHR for all women and babies across Irish maternity units. ${ }^{12}$ There is evidence already that the MN-CMS has made some tasks more efficient for clinicians, such as searching for patient charts (Devin et al., 2021). This shows that a simple but important benefit of an EHR is the ability to move paper records locked in specific organisations to a streamlined digital patient record that can be shared across care settings (Carolan, 2018). In the next

\footnotetext{
12 https://www.ehealthireland.ie/strategic-programmes/mncms/
} 
section, we discuss the most developed EHR in the Irish health system.

\section{Case Study - Irish National Epilepsy Electronic Patient Record}

The establishment of the Irish National Epilepsy Electronic Patient Record and the subsequent development of the electronic patient portal (ePortal) is a good example of innovation in digital healthcare in Ireland (Power et al., 2020). This ePortal, Providing Individualised Services and Care in Epilepsy (PiSCES), provides patients living with epilepsy and their clinicians with a means to engage in more personalised models of care. During the COVID-19 pandemic, the ePortal also facilitated changes in how care is provided (i.e. via telemedicine), improved patient-clinician care, and engendered greater patient self-management (Power et al., 2020). The design of PiSCES provides policymakers with a template in which to design ePortals for other patient populations, or the wider population. Power et al. (2020) discuss the key features of the process:

- a two-factor (2FA) login authentication process, to assist in maintaining data security;

- varying the type of access permission - distinguishing between users who are patients, carers and healthcare professionals;

- My Epilepsy Care Summary, which provides a synopsis of information about the patient that is stored in the National Epilepsy EPR, including seizure types, medications, investigations, possible causes of epilepsy, and medical history - in addition, patients can check who has accessed their EPR;

- My Epilepsy Care Goals - a space to document a patient's ambitions and care goals;

- My Epilepsy Clinic Letters - a clinic letter is automatically generated, and populated with information, following each encounter (visit/consultation) between the patient and their clinician(s).

In addition, the establishment of the National Epilepsy Electronic Patient Record has given rise to a number of important research projects. For example, researchers at the RCSI's FutureNeuro Centre contributed to a large international genome project to provide evidence for epilepsy therapies based on underlying pathophysiology (Abou-Khalil et al., 2018). In the next chapter, we note how, during the COVID-19 pandemic, the Epilepsy EHR assisted integration of telemedicine into the patient's care continuum.

\section{E-Prescribing}

E-prescribing is now a key feature of healthcare in Ireland. On 3 April 2020, the Minister for Health signed legislation that lengthened the validity of prescriptions from six to nine months and removed the requirement for physical/paper copies of prescriptions to be presented to pharmacists (Lynch and O'Leary, 2021). GP 
software systems provided a basis for e-prescriptions through enabling a patient's prescription to be sent directly to pharmacies using the HSE's Healthmail. This is a clinical email service managed by eHealth Ireland that allows clinicians to send and receive clinical patient information in a secure manner. Healthmail enables GPs and those in charge of nursing homes to organise prescriptions for nursing home residents. In addition to reducing the burden placed on individuals, there is evidence that e-prescribing greatly reduces prescribing errors for patients (Devin et al., 2020).

\section{eReferrals}

While electronic referrals (eReferrals) were being developed within the Irish health system before COVID-19, the pandemic saw increased use of eReferrals. This was enabled by Healthlink. GPs can electronically refer patients to both public and private hospitals and clinics. There has been a strong increase in eReferrals in recent years. Figure 3.1 provides information on the average number of general (i.e. not cancer or other speciality) eReferrals made between September 2019 and February 2021. There has been a sharp increase over time: a rise of 62 per cent, from 1,526 eReferrals per day in September 2019 to 2,472 per day in February 2021.

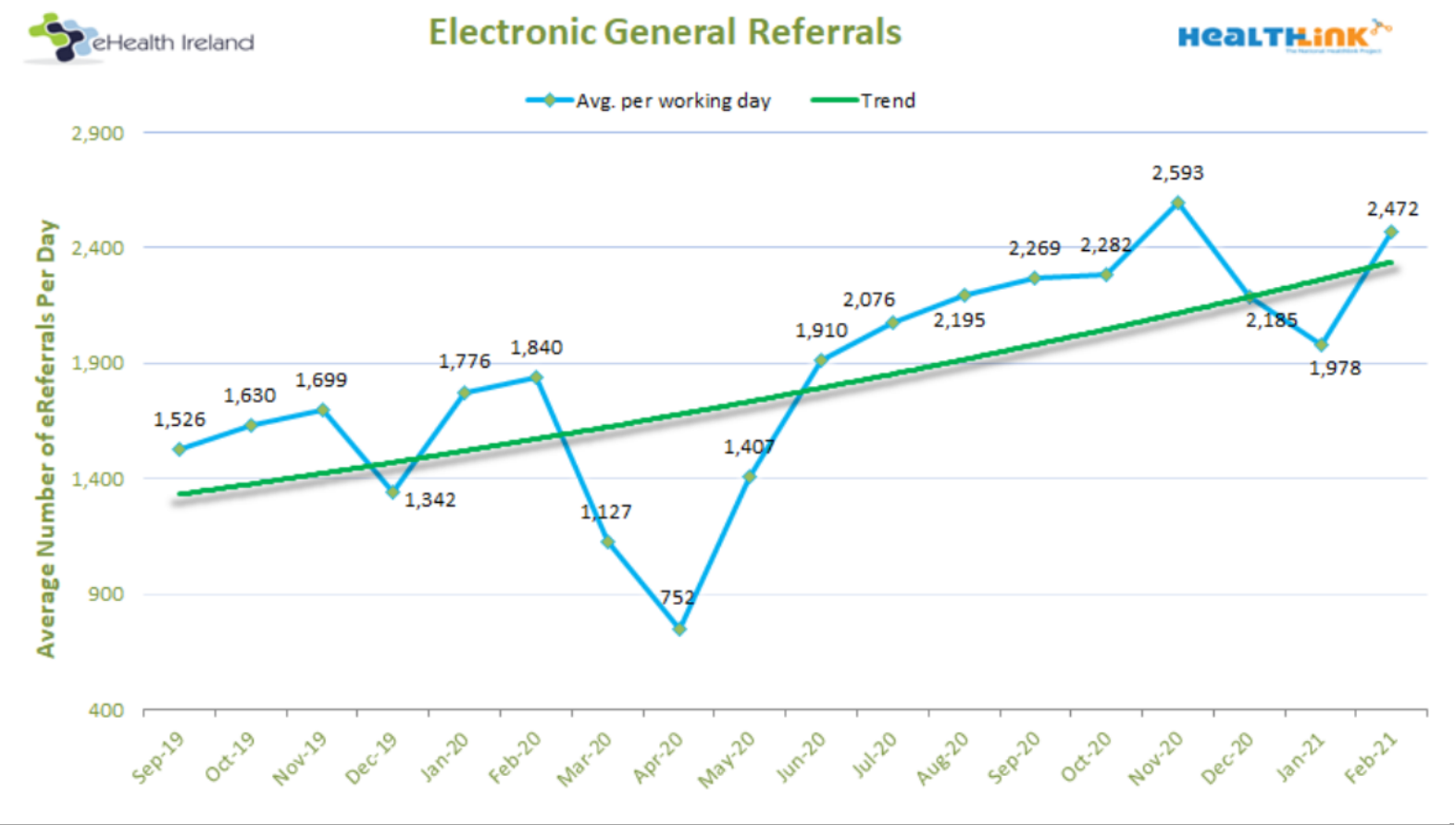

Source: $\quad$ https://www.ehealthireland.ie/a2i-hids-programme/ereferral/latest\%20data/gp-usage/

In the area of cancer services, eReferrals have become commonplace. Figure 3.2 provides information on the annual number of eReferrals for breast, lung, prostate and skin cancer between 2009 and 2021. Once more, a sharp increase over time is 
observed. In 2020, there were over 52,000 eReferrals for cancer services in Ireland, with the majority being for symptomatic breast cancer.

FIGURE 3.2 ELECTRONIC REFERRALS FOR CANCER SERVICES IN IRELAND: 2009-2021

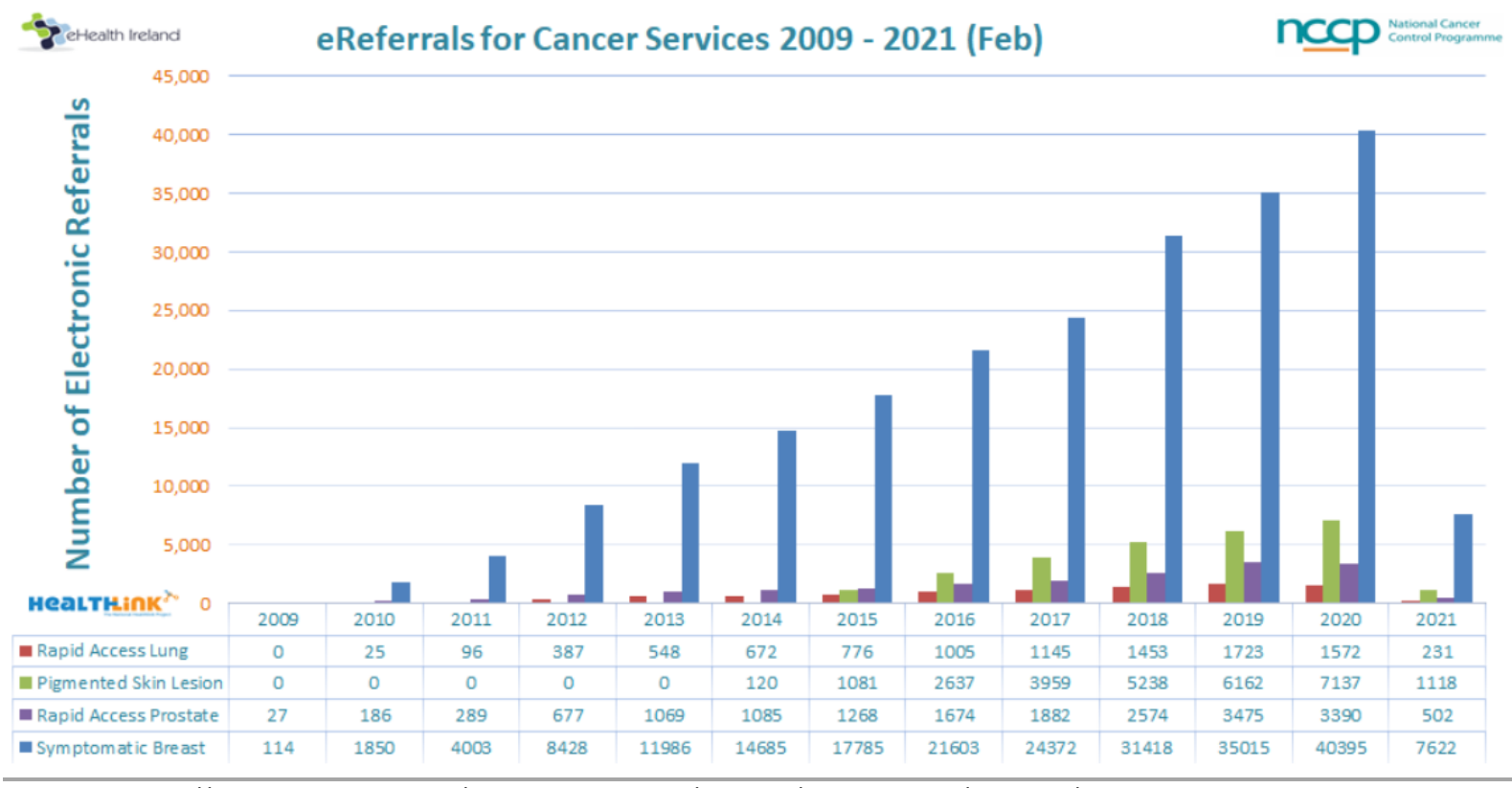

Source: https://www.ehealthireland.ie/a2i-hids-programme/ereferral/latest\%20data/gp-usage/

\subsubsection{Healthcare planning data}

While much of this report has focused on HIS and eHealth, there are several other aspects of the health data infrastructure in Ireland where improvements are required; namely, data used to inform resource and capacity planning.

\section{Healthcare Utilisation Data}

In the previous sections, we described how the lack of IHI and EHRs in Ireland make it difficult to follow people over time and across health and social care services. Other data gaps present challenges for those trying to assemble an accurate picture of health and social care utilisation, and therefore resource and capacity planning.

In the public hospital sector, the Healthcare Pricing Office's (HPOs) Hospital InPatient Enquiry (HIPE) dataset captures information on all discharges in Irish public hospitals. These data also capture extensive information on patients themselves, including their age, gender, address, medical card status, diagnoses, comorbidities, procedures provided, and length of stay in hospital. However, at present, it is difficult to follow patients across multiple episodes of care. This inhibits policymakers' ability to understand important patient outcomes such as readmissions, or overall hospital usage. 
of stay, which is important for a wide range of audit and research purposes, requires patients to be followed across different episodes of care (Busby et al., 2017). This accurate calculation requires the use of continuous inpatient spells (CIPS) to account for the fact that many patients with conditions such as stroke will have a single episode of care, be discharged or transferred, leading to additional episodes of care. Failure to take account of this will result in underestimation of the true hospital usage caused by a condition such as stroke. Table 3.2 highlights findings from Busby et al (2017) showing that the inability to follow patients within a hospital system results in a significant underestimate of hospital resource use for that patient. For stroke patients, examining only episodes of care (spells), which is what HIPE allows, underestimates bed days and length of stay for stroke patients by over 20 per cent (Busby et al., 2017).

TABLE 3.2 COMPARISON OF ADMISSION COUNTS, TOTAL BED DAYS AND MEAN LENGTH OF STAY FOR A CONTINUOUS INPATIENT SPELL (CIPS) AND SINGLE INPATIENT SPELL (BUSBY ET AL., 2017)

\begin{tabular}{|c|c|c|c|c|c|c|c|c|c|}
\hline \multirow[t]{2}{*}{ Condition } & \multicolumn{3}{|c|}{ Hospital stays } & \multicolumn{3}{|c|}{ Total bed days $(1,000 \mathrm{~s})$} & \multicolumn{3}{|c|}{ Mean LOS } \\
\hline & CIPS & Spell & \% Difference & CIPS & Spell & \% Difference & CIPS & Spell & $\%$ Difference $(95 \%$ C) \\
\hline Stroke & 43,526 & 45,167 & 3.8 & 719 & 569 & -20.9 & 16.5 & 126 & $-23.8(-24.3,-23.2)$ \\
\hline Fractured proximal femur & 38,093 & 38,930 & 2.2 & 845 & 697 & -17.5 & 22.2 & 17.9 & $-19.3(-19.8,-18.8)$ \\
\hline Perforated or bleeding ulcer & 53,958 & 54,157 & 0.4 & 246 & 233 & -5.2 & 4.6 & 4.3 & $-5.5(-6.0,-5.0)$ \\
\hline Dehydration and gastroenteritis & 87,270 & 87,506 & 0.3 & 391 & 371 & -5.2 & 4.5 & 4.2 & $-5.5(-5.9,-5,1)$ \\
\hline $\begin{array}{l}\text { Dyspepsia or other stomach } \\
\text { function }\end{array}$ & 14,243 & 14,256 & 0.1 & 18 & 18 & -4.9 & 1.3 & 1.2 & $-5.0(-7.0,-3.5)$ \\
\hline ENT infection & 57,402 & 57,523 & 0.2 & 49 & 48 & -3.5 & 0.9 & 0.8 & $-3.7(-4,4,-3.0)$ \\
\hline
\end{tabular}

Even for a seemingly straightforward outcome such as patient length of stay, the lack of an appropriate HIS and health data infrastructure impedes the ability to capture data correctly. One consequence of this is that international comparisons involving Ireland will be unreliable; length of stay in Ireland will be underestimated when compared with other countries for conditions such as stroke. The introduction of patient identifiers and EHRs into the HIPE data system would help policymakers to better understand where and how best to allocate services.

Outside of the acute public hospital system, the limitations of health data are even more severe, especially in the community care sector. Many of these limitations have been discussed previously (Brick et al., 2020a; Wren et al., 2017). At a most basic level, for public services provided in the community setting, straightforward demographic information such as age, sex and type of care provided are not currently collected or made available for analysis in electronic form (Wren et al., 2017). In many cases, data are still captured on paper-based records, and any data compiled from such sources are typically highly aggregated. This tends to limit the usefulness of these data for even basic research, or to inform planning or operational processes.

Specialist community mental health is one example of an area which will become 
even more important with COVID-19, but suffers from a particularly inadequate data infrastructure. At a rudimentary level, there is no consistent utilisation metric of specialist community mental services in Ireland (Brick et al., 2020a). Mental health services are often provided via multidisciplinary teams, but there is no information on the composition of specialist mental health services in the data. It is unknown how often a single patient accesses specialist mental health services, and whether they ultimately access more acute inpatient mental health services. While attempts have been made since at least 2010 to develop a web-based mental health information application (WISDOM) to record information on patients using community mental health services, this solution never materialised (Brick et al., 2020a). Similar examples can be found across other community care service sectors in Ireland.

\section{Private healthcare}

Thus far this section has concentrated on the HIS and health data infrastructure in the public healthcare system in Ireland. However, a substantial role is played by private healthcare providers. For example, GPs are private operators who provide care to public patients through the General Medical Services (GMS) scheme. Similarly, a large role is played by private therapists (Eighan et al., 2017), and most home support to older people is provided by private providers (Walsh and Lyons, 2021). A large proportion of acute hospital care is also provided by private hospitals (Wren et al., 2017). During COVID-19, the plans to cope with a surge of hospital demand from COVID-19 cases led to the effective nationalisation of the private hospitals (Walsh et al., 2020).

An integrated HIS in the Irish healthcare system should encompass private providers and facilities where possible. This view is shared by eHealth Ireland. Previously eHealth has worked with private providers such as GPs, pharmacies and private hospitals so they can access and contribute to the National Shared Record to bring about better integration capability of HIS in Ireland (HSE, 2016). For some services, this is already occurring. Healthlink enables GPs to transfer patient information securely to public and private hospitals and clinics. Therefore, the eReferrals and e-Prescribing services are enabled across all GP management systems and allow for communication with private facilities and pharmacists. ${ }^{13}$

However, despite some integration occurring across public and private healthcare providers in Ireland, many significant limitations with the integration of private providers in a national HIS remain. At a basic level, there is often little information on how much care is provided by, and the levels of resources available to, private healthcare providers. For example, there is no centralised database for general practice utilisation, private community care, and private hospital care. This makes planning for the public, as well as the broader health system, very difficult. A

\footnotetext{
${ }^{13}$ https://www.ehealthireland.ie/a2i-hids-programme/healthlink/
} 
number of ESRI studies referenced in this report have used various information sources to estimate private provision of health and social care in Ireland. Similarly, the capabilities of private facilities, for example, to integrate with a national EHR are unknown.

\section{Healthcare system planning during COVID-19}

A crucial issue that was apparent from the outset of the COVID-19 pandemic in Ireland was the low level of hospital bed and intensive-care bed capacity across the country, especially when compared to European peers (Walsh et al., 2020). This made the efficient allocation of hospital resources a matter of absolute priority for decision-makers. To facilitate an informed response, a number of modifications were made to the collection and reporting of healthcare data, and the introduction of some new management systems. HIPE data systems were quickly modified to better capture COVID-19 hospital admissions and care to provide the National Public Health Emergency Team (NPHET) with information to inform the planning of hospital care during COVID-19. Work by the Irish Epidemiological Modelling Advisory Group (IEMAG) has been able to use HIPE to examine COVID-19 hospitalisations, length of stay and geographic differences (Keegan and Lyons, 2021a) as well as develop a model to plan hospital services in Ireland (Keegan and Lyons, 2021b).

Similarly, there were speedy changes to data management and reporting on the critical-care beds in hospitals. The National Office of Clinical Audit (NOCA) established an 'ICU (Intensive Care Unit) Bed Information System' at the beginning of the COVID-19 pandemic. Working with ICT partners, a new web-based bed data system enabled policymakers to follow critical-care beds that were open and staffed, occupied, had patients that were invasively ventilated, or beds that were closed or potentially available. ${ }^{14}$ As these data are available at hospital level, they were also used to analyse available capacity at a regional level.

The Health Protection Surveillance Centre (HPSC) is Ireland's public health centre for the surveillance of communicable diseases. Along with other policymakers, it adapted its data systems to collect information on COVID-19. Much of the data collected and collated by the HPSC is now provided to researchers and the public through the Government's COVID-19 data hub ${ }^{15}$. The Central Statistics Office (CSO) provides a COVID-19 Information Hub, reporting on changing aspects of health, the economy and society since the outbreak. A recent report, published before COVID19 , highlighted the need 'to improve technology within the service so as to enable key public health activities such as surveillance and health protection control activities' (Crowe Horwatch, 2018). Many of the improvements to the system, and greater understanding of what will be needed to better respond to future public

\footnotetext{
${ }^{14}$ https://www.noca.ie/news/dr-rory-dwyer-provides-an-update-on-the-timely-introduction-of-the-icu-bed
}

15 https://covid19ireland-geohive.hub.arcgis.com/ 
health crises, should be used to modernise the public health data infrastructure in Ireland.

In addition to changes made to existing data highlighted above, below we highlight some of the ICT innovations and improvements that occurred in Ireland to respond to the COVID-19 health emergency. Since we are still in the midst of the pandemic, and rigorous evaluations and studies examining interventions have not yet been published, it is impossible to cover and evaluate all of the changes in a robust fashion. Therefore, in the box below, we highlight as a case study some key ICT changes which have occurred in Ireland. This segment was informed by communication with stakeholders involved in the changes, particularly Microsoft Ireland and the HSE which worked together to design and implement much of the transformation. 
The sudden emergence of threats posed by the COVID-19 pandemic in 2020 meant that health services globally faced unprecedented resource challenges in terms of demand for services, staff numbers and technological capability. The pandemic ultimately served as a catalyst for rapid change in many organisations, including the HSE. In addition to organisational challenges, the HSE became the centre of a high-level group responsible for delivering reliable information and facts to the general public and key decision-makers.

To respond to these rapidly evolving demands and challenges, the HSE embraced several new digital tools that provide flexibility, scale and responsiveness, but also helped the organisation to process and derive insights from significant amounts of data - all through the use of cloud-based systems. The roll-out of these digital solutions assisted in delivering insights, facts and data in real time to enable decision-making, as well as support resourcing planning, and dissemination of information to the public.

There are five key elements to the HSE's technological response to COVID-19:

1. A cloud-based Microsoft Azure Data Lake is used to support data and analytics requirements.

2. The Covid Care Tracker was created to facilitate contact tracing. This was constructed as a Minimum Viable Product within two weeks.

3. A Microsoft Power Apps-based Portal was established to allow laboratories undertaking COVID-19 testing to report daily activity and capacity to the HSE and the Department of Health.

4. A Microsoft Power Business Intelligence (BI) Reporting Dashboard provides data visualisation and the creation of reports to promote insight and facilitate data-driven decision-making.

5. A Health Bot for managing simple citizen queries online.

\section{1) Cloud-Based Systems}

The Data Lake, built on the Microsoft Azure cloud-based platform, aided the collation of data from over 30 data systems and sources, including hospital testing laboratories, contact tracing centres, and critical-care bed data. Information collated was synthesised through dashboards to inform real-time decision-making across the system. This information-gathering and data synthesis supported the National Public Health Emergency Team (NPHET) in modelling COVID-19.

\section{2) COVID Care Tracker}

The Covid Care Tracker enabled clinicians and contact tracers to engage with COVID-19 cases and also helps to record contacts of cases. Importantly, it reduced the reliance on the paper-based process of recording cases and contacts, and helped to regularly inform estimation of the COVID-19 reproductive number.

\section{3) COVID-19 Case Numbers}

Microsoft Power Apps was used to build a portal to allow laboratories undertaking COVID-19 testing to report daily testing numbers and case numbers.

\section{4) Reporting Dashboard}

A Reporting Dashboard for COVID-19 was developed using Microsoft BI. This provided regular updates on COVID-19 incidence. It was also used at local provider levels to inform resource planning, and, for example, provided real-time information on critical-care bed capacity.

\section{5) Artificial Intelligence - Symptom Health Chatbot}

A Health Chatbot ${ }^{16}$ using Al-based technology was designed with input from clinicians to allow people to ask triagetype questions about COVID-19. This was employed to help reduce the strain on clinicians and HSE staff responding to COVID-19-related enquiries. After answering triage questions, people were recommended a subsequent course of action, such as a follow-up call or isolation. Upon implementation, the Health Chatbot was receiving 30,000 unique users each day.

Sources: Communication with Microsoft Ireland and the HSE.

There are many other examples of health technologies adopted in Ireland during the COVID-19 pandemic, including in the private sector. For example, the COVID19 Tracker smartphone app was established to track and limit the spread of COVID19. It has been highlighted as a success of the COVID-19 response (Kennelly et al.,

\footnotetext{
${ }^{16}$ https://www.tekenable.ie/building-software-solutions-to-aid-in-the-battle-against-the-covid-19-pandemic-in-ireland/
} 
2020). However, there is evidence that the full capabilities of the app to reduce the spread of COVID-19 were limited by the extent to which it was used. Between October 2020 and April 2021 only 25 per cent of the expected number of testedpositive app users uploaded the details required for that user's app to help identify close contacts (Farrell and Leith, 2021). However, due to the pandemic still ongoing at the time of writing, it is difficult to discuss or evaluate other interventions.

\subsection{CONCLUSION}

Gaps remain in Ireland's HIS, eHealth and health data infrastructure. Some improvements have occurred in recent years, not least the establishment of eHealth Ireland. The successful rollout of eReferrals, e-prescribing, and the Irish National Epilepsy Electronic Patient Record provide a basis for promoting continued development of a HIS. Similarly, COVID-19 has expedited a number of significant advancements.

Policymakers were able to modify and change some important datasets, such as HIPE, to better inform planning of healthcare services for COVID-19. Moreover, pre-existing eHealth tools such as e-Prescribing and eReferrals, and telemedicine were increasingly adopted and used over the pandemic period. Working with partners in the public and private sectors, policymakers also adopted many modern health technologies. New health technologies such as cloud-based data lake platforms were used to collect and collate COVID-19 data in real time. AIbased technology using clinical input was implemented through the COVID-19 triage Health Chatbot. The adoption of these innovations shows what the system is capable of implementing in a short time. Further building upon and strengthening these improvements and successes will be required to continue to navigate the course of the pandemic and to meet the healthcare challenges of the post-pandemic era. 



\section{TELEMEDICINE}

\subsection{INTRODUCTION}

This chapter examines a specific domain of HIS and eHealth - telemedicine. During COVID-19, telemedicine has seen increased use, born out of necessity. This chapter highlights some of the recent changes in the adoption of telemedicine and considers the implications for telemedicine in the future. We limit the scope of the analysis to key areas relevant to the Irish healthcare system, and where data are available.

\subsection{OVERVIEW}

Telemedicine involves the use of technologies to deliver healthcare remotely or at a distance (Wootton, 2001). It can occur via the telephone, video conferencing, mobile applications, or remote patient monitoring. In the last decade, telemedicine has gradually emerged as an increasing component of healthcare across OECD countries (Hashiguchi, 2020). The onset of the COVID-19 pandemic has expedited the adoption of telemedicine to aid communication between patients and clinicians in a socially distanced, safe manner. The increased use of telemedicine during COVID-19 may provide a catalyst for greater integration of telemedicine as an option for care services in the future. eHealth Ireland established a National Virtual Health Team to provide telemedicine/telehealth solutions and support telemedicine across different health and social care services. ${ }^{17}$ Guidance and solutions have been published to support communication and collaboration across the health service. ${ }^{18}$

\subsection{TELEMEDICINE IN GENERAL PRACTICE}

As a result of the COVID-19 pandemic, the introduction of lockdowns, and the reticence of some people to visit healthcare facilities, healthcare use dwindled (Brick et al., 2020b), while international evidence has shown a sharp increase in virtual health, or telemedicine consultations (Monaghesh and Hajizadeh, 2020). In this section, we examine the increase in use of telemedicine in general practice during COVID-19. Due to the detailed administrative information available on general practice in England, we first examine data from general practice in England, and also show evidence from Ireland.

Figure 4.1 provides information on general practice consultations (visits) that were provided face-to face or via telephone/video between January 2020 and January 2021 in England. Face-to-face consultations occur predominantly within the practice, though some occur in a patient's home or in residential care facilities. We

17 https://www.ehealthireland.ie/national-virtual-health-team/

18 https://healthservice.hse.ie/staff/coronavirus/working-from-home/virtual-health/virtual-health.html 
characterise those consultations that occur via telephone or video call as telemedicine. ${ }^{19}$ Telephone calls account for the vast majority of telemedicine consultations. This period covers both the pre-COVID-19 period and the COVID-19 pandemic. A dramatic change in the method of consultation that corresponds with the onset of the COVID-19 pandemic is seen. In January 2020, over 80 per cent of general practice consultations in England were face-to-face, with only 14 per cent being telemedicine. However, by April 2020, 47 per cent and 48 per cent of consultations were via face-to-face and telemedicine respectively. Over the succeeding months, while the percentage of telemedicine consultations reduced slightly, approximately 40 per cent of all general practice consultations continued via telemedicine.

\section{FIGURE 4.1 GENERAL PRACTICE CONSULTATIONS IN ENGLAND: JANUARY 2020 - JANUARY 2021}

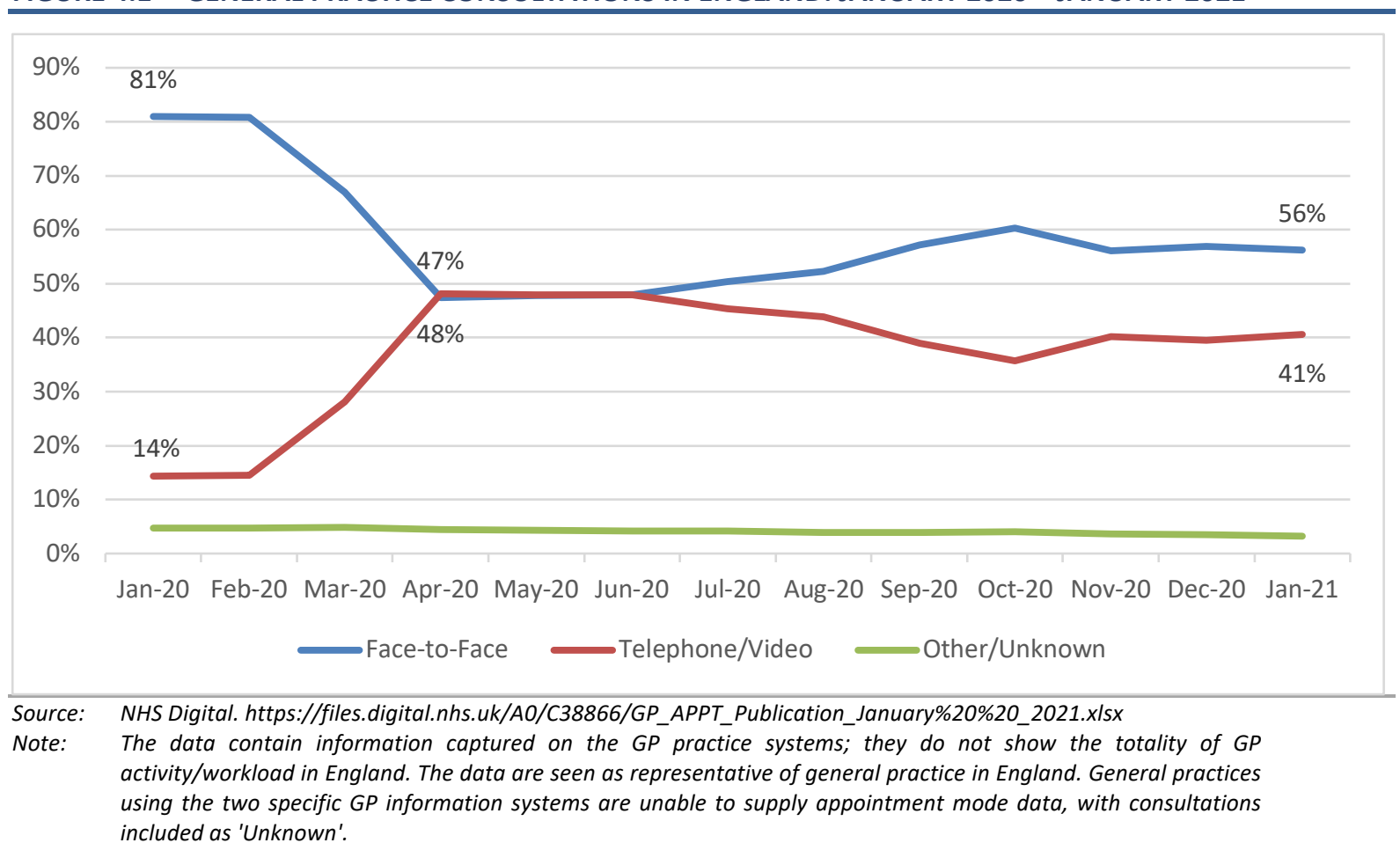

Figure 4.1 illustrates that telemedicine has been an important channel for the provision of general practice care during COVID-19 nationally in England. However, Figure 4.2 highlights regional variation as measured by clinical commissioning groups (CCGs). ${ }^{20}$ In January 2021, there was significant variation in telemedicine across regions. In approximately 15 per cent of the CCGs, more than half of general practice consultations in January 2021 were via telemedicine. However, in other

\footnotetext{
19 NHS Digital states that appointments marked as online, video or video conference are shown as 'Online / Video' in their data, as are non-video-based online consultations such as live chat or VOIP and video-based appointments. It also states that it is likely that many video consultations begin as a telephone appointment, then switch to video, and therefore may be undercounted.
}

${ }^{20}$ CCGs are geographic groups of general practices that have the authority to commission care for the patients in their geographic region. 
regions, telemedicine constituted a much lower percentage of consultations. This highlights that some regions may be better prepared for telemedicine and also be more likely to want to adopt it.

\section{FIGURE 4.2 GENERAL PRACTICE CONSULTATIONS ACROSS CLINICAL COMMISSIONING GROUPS IN ENGLAND: JANUARY 2021}

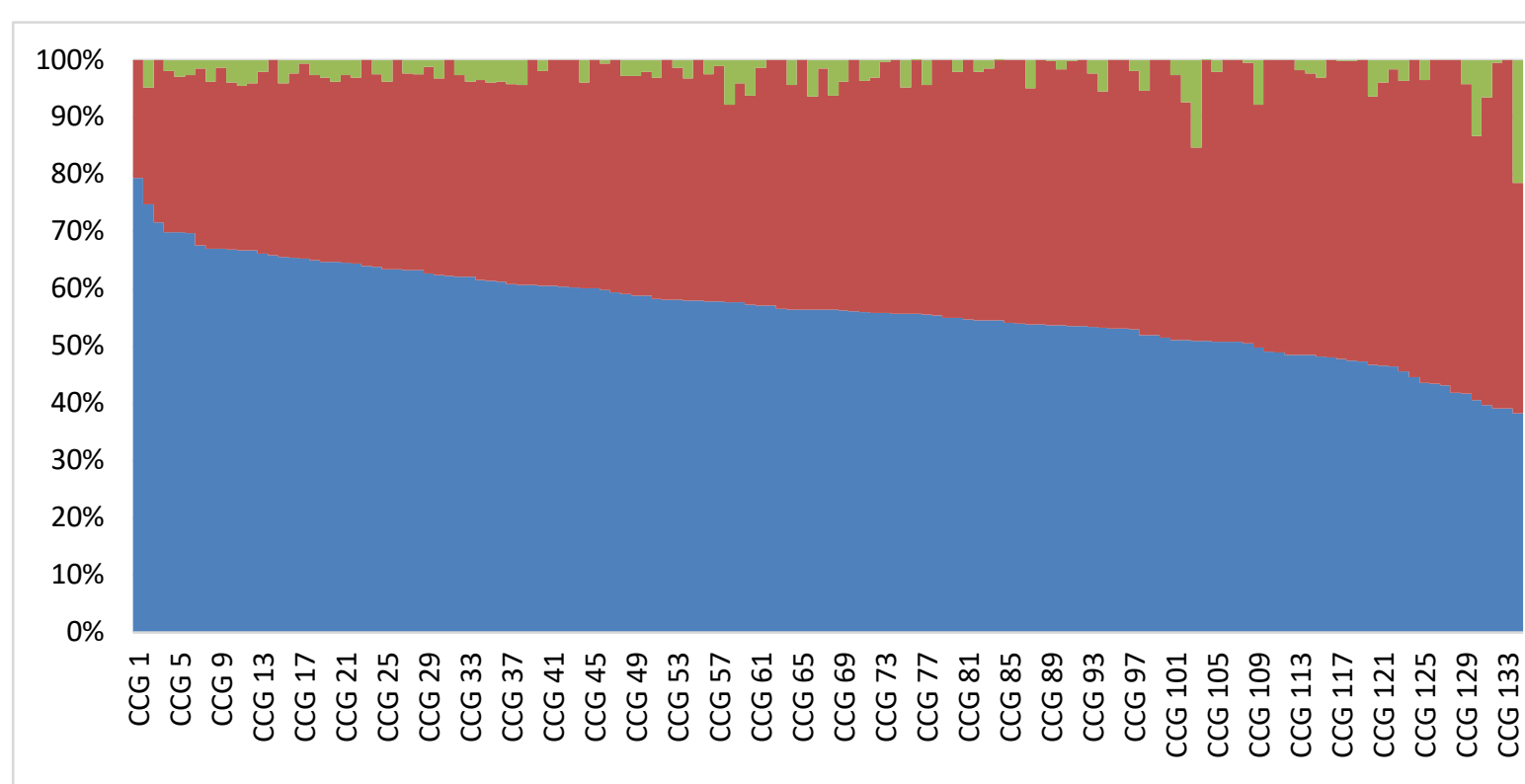

Face-to-Face $\quad$ Telephone/Video Other/Unknown

Source: https://files.digital.nhs.uk/AO/C38866/GP_APPT Publication_January\%20\%20 2021.xlsx

Note: The data contain information captured on the GP practice systems; it does not show the totality of GP activity/workload in England. The data are seen as representative of general practice in England. General practices using the two specific GP information systems are unable to supply appointment mode data, with consultations included as 'Unknown'.

The increase in the use of telemedicine in general practice is indicative of greater use of telemedicine in the NHS more generally during COVID-19. Almost 60 per cent of UK adults who used the NHS at the beginning of the COVID-19 pandemic, did so using technology, in a new way or more frequently than before (Horton et al., 2021).

While it was not possible to examine similar administrative data for Ireland in this study, a comparable pattern occurred in Ireland. In two studies (Homeniuk and Collins, 2021; Collins and Homeniuk, 2021) examining 526 general practices in Ireland (a large percentage of all practices), found that pre-COVID-19, telemedicine general practice use was similar across England and Ireland; in February 2020, 10 per cent of consultations (visits) were via telemedicine (Collins and Homeniuk, 2021). Of note, the study found that 17 per cent of practice nurse visits were undertaken via telemedicine (Collins and Homeniuk, 2021). By June 2020, 57 per cent of GP consultations were undertaken via telemedicine (Homeniuk and Collins, 2021), higher than rates seen in England. Collins and Homeniuk (2021) also found that 38 per cent of the general practices did not have a telemedicine option. The ability to conduct telemedicine during COVID-19 was likely to be more restricted for those general practices without telemedicine facilities in place. 


\subsection{TELEMEDICINE IN HOSPITAL CARE}

In October 2021, the Medical Council of Ireland commissioned a survey of telemedicine use across all healthcare in Ireland. ${ }^{21}$ This survey found that, prior to the COVID-19 pandemic, only 4 per cent of the Irish population had used telemedicine. However, by October 2021 this had risen to 21 per cent. While the scope of the Medical Council's survey was limited, the results indicate the rapid change in how Irish people were using healthcare since the onset of the COVID-19 pandemic. This is also supported by the increased use of telemedicine in the Irish hospital system.

Figure 4.3 presents the key findings from an analysis which examined increased use of telemedicine for outpatient department (OPD) care for people with epilepsy (Banks et al., 2021). The researchers used data from the Irish National Epilepsy Electronic Patient Record and the two epilepsy centres in Beaumont Hospital Dublin and St James's Hospital Dublin. The data, collated using Microsoft Power BI Analytics, allowed the authors to examine the impact that COVID-19 had on 3,346 OPD consultations by patients with epilepsy that occurred between 23 December 2019 and 24 June 2020. The results were partitioned into a pre-COVID-19 period (23 December 2019 - 23 March 2020), and during the early months of the COVID19 period (24 March 2020 - 24 June 2020). Using the information provided, Figure 4.3 highlights the number of traditional face-to-face OPD clinics and telemedicine (telephone encounters or virtual clinics via telephone). It is clear that there was a large change in OPD consultations by patients with epilepsy. Pre-COVID-19, 712 out of 1,653 OPD consultations (43\%) were via face-to-face OPD clinics, with 627 being telephone encounters (28\%). However, after the onset of COVID-19, the mode of interaction changed considerably. Between 24 March and 24 June 2020, only 74 (4\%) of consultations were via face-to-face OPD clinics, with 1,503 (89\%) undertaken via telephone or virtual clinic.

\footnotetext{
${ }^{21}$ https://www.medicalcouncil.ie/news-and-publications/press-releases/press-release/items/five-fold-increase-in-use-oftelemedicine-in-ireland-since-start-of-pandemic.html
} 
FIGURE 4.3 BREAKDOWN OF OUTPATIENT DEPARTMENT (OPD) ENCOUNTERS OF EPILEPSY PATIENTS BY ENCOUNTER TYPE PRE AND DURING COVID-19 (BANKS ET AL., 2021)

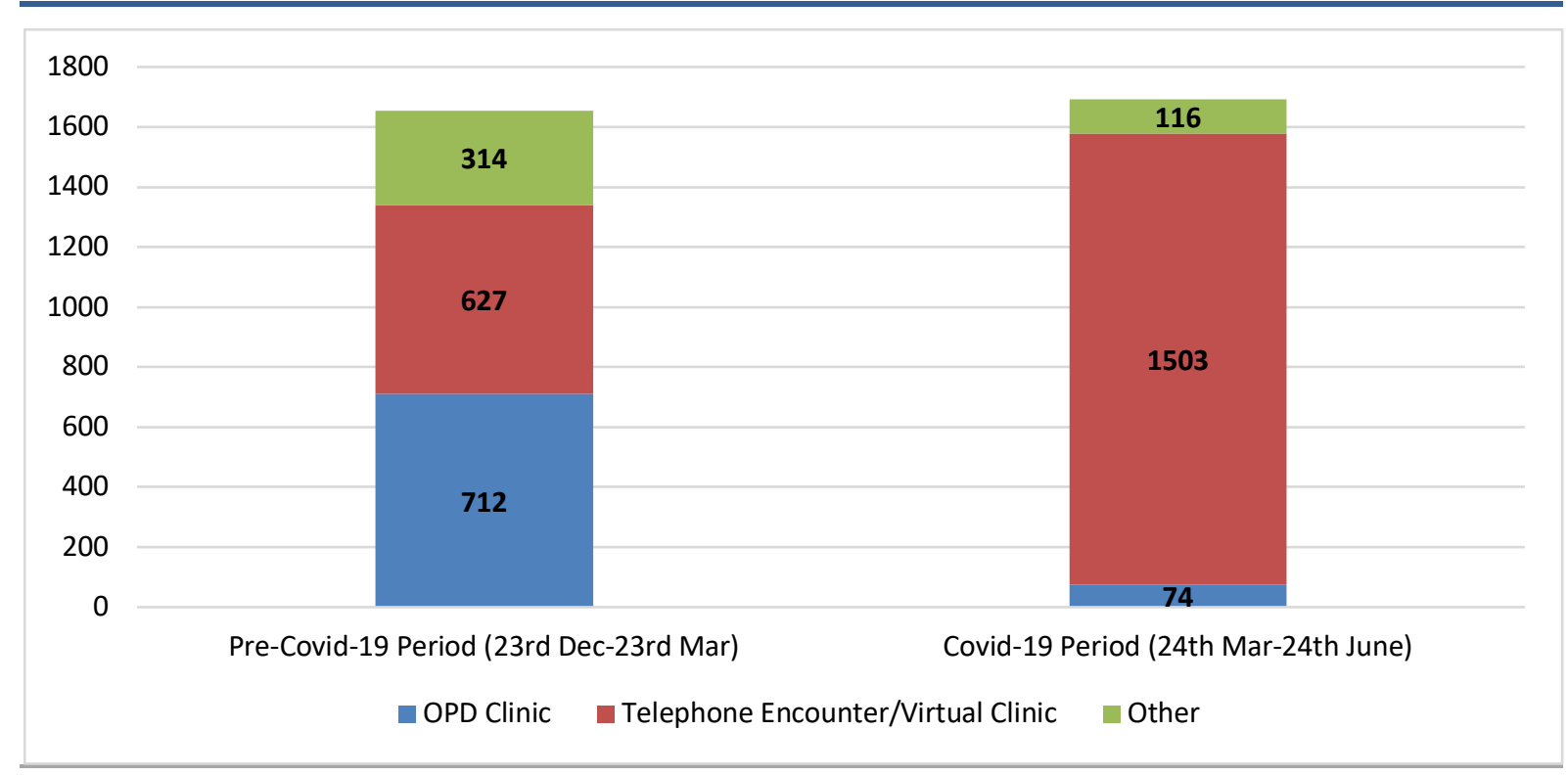

Source: Banks et al., 2021.

Banks et al. (2021) also found that the vast majority of clinicians who undertook the OPD consultations felt that the patient was appropriate for a virtual encounter ( 90\%), and they were happy that the patient could continue their routine care virtually ( 75\%) (Banks et al., 2021). In addition, the authors found that a majority of patients with epilepsy were happy to have their care provided virtually if their condition remained stable.

One other important insight from this work is that, while telephone interactions were clearly favoured by many, increasing the use of video calls was suggested (Banks et al., 2021). This has been supported by recent research on telemedicine in primary care (Greenhalgh et al., 2020). Greenhalgh et al. (2020) argued that video calls provide clinicians and patients with additional visual cues and therapeutic presence during the consultation.

The results shown above for epilepsy care have also been seen for other outpatient services in Ireland. Oncology services have also transitioned towards telemedicine (O'Reilly et al., 2021). Virtual oncology clinics have been shown to be a good substitute for in-person hospital visits during COVID-19; 61 per cent of respondents were 'very relieved' to have avoided hospital by using virtual oncology clinics (O'Reilly et al., 2021).

\subsection{TELEMEDICINE IN THE FUTURE}

Telemedicine is now an important part of primary and hospital care services. There is evidence of an appetite among patients and clinicians in Ireland for virtual care options to continue into the future. As we have highlighted above, evidence from 
the Medical Council (and those living with epilepsy and oncology patients) shows that 55 per cent of people said they would use telemedicine more frequently in the future (Medical Council of Ireland, 2020). In January 2020, NHS England released a toolkit on online consultations in primary care. This toolkit followed the NHS Long Term Plan which committed to a digital first primary care, and a commitment that by 2023/24 every patient in England will be able to access a digital first primary care offer (Bakhai et al., 2020). This plan commits to at least 25 per cent of appointments being available via online booking, and that all patients will have the right to online consultations by April 2020 and video consultation by April 2021.

While telemedicine and digital health may increase in the future, the increased use of this method is not necessarily a panacea for improving patient outcomes. There is ambiguous evidence as to whether digital health can improve outcomes, reduce costs or burdens on patients (particularly those with lower digital health literacy e.g. older people and those with lower education levels), and reduce the pressure on clinicians. Similarly, evidence shows that, while there has been a dramatic increase in telemedicine during COVID-19, it was mainly observed among higher socioeconomic groups, giving rise to concerns about the widening of disparities in healthcare access (Cantor et al., 2021).

There is evidence that targeted use of telemedicine and digital health is likely to realise the best outcomes. Digital telemedicine interventions have been shown, for example, to improve measures of disease control in chronic-illness patients, but have not demonstrated benefits for patients' overall health (Kraef et al., 2020). In addition, the form that telemedicine takes is important. Recent research has found that, for many patients, secure messaging from clinicians is favoured over video consultations (Stamenova et al., 2020).

In recent years, new general practice providers in Ireland such as MyClinic.ie are increasingly being used to provide GP and practice nurse visits via phone or video conferencing, and a mobile app to follow people's health. While the benefits to patients in terms of accessing a quick convenient consultation via telemedicine may be substantial, some clinicians have spoken about the need for a cautious approach to telemedicine. Medical Council president, Dr Rita Doyle, cautioned that telemedicine consultations, especially with a GP who is not the patient's regular doctor, can increase the amount of inappropriate prescriptions (Reilly, 2019). Similar points have been made by other GPs in Ireland.

One other open debate concerning telemedicine is whether, instead of substituting care across communication modes, it ends up increasing overall use in an unnecessary manner, and overwhelming clinicians with requests. However, there is recent evidence that telemedicine does not necessarily increase overall general practice use, but rather is used as a substitute for face-to-face consultations (Stamenova et al., 2020). But the importance of patients being connected with 
their own, regular clinician is acknowledged (Stamenova et al., 2020). In this respect, within general practice for example, the benefits of telemedicine may be seen when it affords more regular visiting, improved access, and continuity of care between patients and existing clinicians. This could be further enhanced through the use of an EHR and ePortal, as exists for epilepsy patients in Ireland (Power et al., 2020). However, other evidence has shown that approximately 40 per cent of NHS users and a third of NHS staff felt that new technologies, such as telemedicine, were 'worse' than traditional models of care (Horton et al., 2021).

Previous ESRI research has shown that, concerning access to general practice care, and community care more generally, there is, in effect, a 'postcode lottery' (Smith et al., 2019). In line with recommendations made by the Irish College of General Practitioners (ICGP) and others (Primary Care Partnership, 2016), consultations with patients, especially consultations that require multidisciplinary teams to 'attend', could be undertaken using telemedicine or 'virtual attendance' by the GP. Where telemedicine becomes a key feature of general practice, it may reduce the amount of travel for routine consultations by people in rural areas and allow for better allocation of time by GPs and nurses in areas with a lower supply of care.

Accordingly, in December 2020, the Medical Council of Ireland released new telemedicine guidance for doctors (Medical Council of Ireland, 2020). It highlighted the important role that telemedicine has played during the COVID-19 pandemic in minimising the transmission risks of COVID-19 to healthcare workers and other patients. In particular, it pointed to the use of telemedicine to help maintain continuity of care for patients. However, telemedicine consultations were less appropriate than face-to-face visits for urgent situations or for patients with complex care needs, where a physical examination was required, when sensitive topics needed to be discussed, and where people had limited or poor access to devices (e.g. smartphone, tablet) or the internet (Medical Council of Ireland, 2020).

In addition to the guidance from the Medical Council, implementing telemedicine in the future will require greater education on the process for clinicians and patients, an understanding that telemedicine will not be appropriate for all consultations, and that some specific population groups, such as older people, may be unable to access the service. Recent work provides a framework and suggested strategies for implementing telemedicine systems to improve health equity (Samuels-Kalow et al., 2021). Similar frameworks should be adopted in Ireland. Telehealth requires changes in management effort and the redesign of existing models of care, as well as training of clinicians (Smith et al., 2020). 
60 | Developments in Healthcare Information Systems in Ireland and Internationally 


\section{CONCLUSIONS}

\subsection{INTRODUCTION}

Developing robust and agile health information systems (HIS) and deploying digital health solutions as part of healthcare service provisions are strategic priorities for health systems. Increased healthcare use, growing healthcare expenditures, and the need to react to public health emergences such as COVID-19 necessitate a greater role for HIS and health informatics. The technological developments that have occurred recently have led to a rapid development of healthcare technologies for patients, clinicians and policymakers to use. However, where a healthcare system fails to embrace advanced health information and management systems, many benefits that could be garnered from new technology may not be realised.

While many health systems, including the Irish system, have been slow to implement a HIS and implement modern health data infrastructures, the COVID19 pandemic has been a catalyst for adopting health technology. It became clear that a country's ability to react to COVID-19 was in part dependent on the ability of healthcare policymakers to make quick and informed decisions.

This report aimed to provide a high-level overview of the current health information landscape in Ireland, and to identify features in other healthcare systems that could be adopted in Ireland to allow for a more modern healthcare system to be developed here. Therefore, as the scope of HIS, eHealth and health technology is very broad, we chose to focus on features that are more pertinent to informing healthcare policymakers in Ireland.

\subsection{INTERNATIONAL EVIDENCE}

We considered and documented key features of HIS capabilities of contemporary international healthcare systems to provide a context in which to view current HIS arrangements in Ireland. From this review, a number of common features of successful HIS were found. First, the nationwide rollout of an IHI such as the mandated $\mathrm{CHI}$ in Scotland; the $\mathrm{CHI}$ number uniquely identifies a person on the national register and is included across various electronic medical recording systems across different services in the NHS Scotland system. It also is a primary source of demographic information for local health boards. The latter enables better resource allocation of healthcare services as local services can be provided to meet the needs of local populations.

Second, in addition to an $\mathrm{IHI}$, the establishment of a national EHR, to provide systems with the ability to join up information across different parts of the healthcare system, is important. The interoperability of various healthcare data systems is crucial in order to maximise the potential benefits of health informatics. 
In England, the NHS Spine is a central database that joins together healthcare IT systems across different services and providers, thereby allowing the secure sharing of information such as an e-Referral Service (NHS Digital, 2019). There is a similar scheme in the Netherlands, AORTA, while the HIS in New Zealand, the country that has arguably been the most successful in combatting COVID-19, also ensured quick responses to the pandemic. New Zealand could link its National Health Index (NHI) to EpiSurv, a database of COVID-19 cases with information on laboratory data, clinical data and clinical outcomes. The use of EHRs as a basis of 'big data' has also proved invaluable for research on patient populations to be undertaken. It has been recognised that big data and the use of $M L$ and $A l$ to undertake research has not been a panacea for identifying policies that could, for example, reduce healthcare expenditure in complex patient groups (Stokes et al., 2021). Nevertheless, there is evidence that these big data can be used to identify better care pathways for patients (Boland et al., 2015; Ferrone et al., 2019).

Third, the ability of different systems across the health system to communicate and integrate with each other is vital. Without this, the use of EHRs, big data and health technologies is reduced. Countries with decentralised health systems (e.g. Canada), or with several systems unable to be integrated (NHS England), demonstrate that taking a holistic view of the health system (both public and private) is needed when designing a HIS that is fully robust and interoperable.

A final consideration from international experiences of developing effective HIS has been instilling confidence and assurance among the general population as data subjects that their information is collected for specific purposes and is used and stored in a secure and safe manner. One function of a modern HIS is that it can also provide patients with a means to use their own data to inform their, and their clinicians', decision-making on their care pathways. On a related point, we also show that the use of telemedicine during COVID-19 has meant that patients could receive care remotely. Without this service, the unmet need for healthcare services during COVID-19 would likely have been larger.

\subsection{THE HEALTH DATA LANDSCAPE IN IRELAND}

We showed that, across the Irish health system, there are significant gaps in the HIS, health data infrastructure, and the use of health technologies. Even basic information, such as having a systematic minimum dataset for public healthcare services provided in the community, is lacking. In addition, there is fragmentation between public and private healthcare providers. Similarly, poor public health data infrastructure has been highlighted during the COVID-19 pandemic. ${ }^{22}$

The integration of an $\mathrm{IHI}$ and national EHR into the Irish healthcare system could help transform the health data landscape. This has been acknowledged by

\footnotetext{
22 https://www.medicalindependent.ie/stone-age-systems-hamper-irelands-public-health-specialists/
} 
policymakers (HSE, 2016). HIQA has developed recommendations to help develop a national EHR (HIQA, 2020). The establishment of eHealth Ireland has been a significant step in the HIS in Ireland. Funding increases have also occurred, and in 2021 , the total eHealth and ICT budget was $€ 120$ million, double the budget of 2018. Previous HSE reports have highlighted that more than $€ 800$ million over a 10-year period would be required for the rollout of ICT in Ireland (HSE, 2016). However, as the health budget has also increased, we estimate that less than 0.8 per cent of the budget in 2021 will be spent on ICT and eHealth.

Improvements in adopting and integrating eHealth solutions have also been made. As the report highlights, eReferrals and e-Prescribing are now common features of the Irish healthcare system. The development of an EHR for people with epilepsy has also had a beneficial impact in terms of providing appropriate care for this population. The Irish National Epilepsy Electronic Patient Record (EPR) and the subsequent development of the electronic patient portal (ePortal) have facilitated changes in patients care pathways and improved patient-clinician contact, and has engendered greater patient self-management (Power et al., 2020). These structures provide Irish policymakers with a template for expanding an EHR to other patient populations, and ultimately to establish a national EHR. Following this, data analytics platforms such as OPENSafely (in England) could provide invaluable research findings to patients, clinicians and policymakers to help plan healthcare services and improve clinical care.

More generally, this report also underscores several important facets of the Irish healthcare system where there are considerable gaps in the recording, collection and collation of important patient care data across the public and private sectors, particularly with regard to healthcare utilisation and expenditures. A glaring example is that, due to that lack of unique patient identifiers, the HIPE dataset cannot follow patients across hospitals. This prevents adequate tracking or followup of discharges across multiple episodes of care. There are also severe deficiencies in data made available from the primary, social and community care sectors, which would be useful for healthcare planning. Furthermore, many private providers thus far provide little information on the amount and type of care they perform. This gap in knowledge around private healthcare poses a large challenge to the development of a robust and broad HIS in Ireland, arguably more so than in those countries examined in Chapter 2.

The sharing of accurate information to coordinate the health sector response and to effectively communicate public health advice and guidelines hinges on reliable data and HIS. A remarkable feature of the pandemic has been the general public's interest in, and engagement with, health statistics and data, which may serve to bolster the case for continued improvements, investment and public buy-in for modern HIS and health data collection. The experience of COVID-19 highlighted the importance of communicating accurate, regular health information to the 
public so that they could use this information to make better-informed decisions more generally.

\subsection{TELEMEDICINE}

In addition to spurring HIS and health data improvements, the COVID-19 pandemic has had a large impact on how people interact with the healthcare system. It has led to telemedicine becoming a central feature of healthcare in Ireland, the NHS in the UK, and internationally. The report highlights that, across primary care (general practice) and acute care, telemedicine consultations have become as common as face-to-face consultations. Evidence from NHS England shows that telemedicine increased from 14 per cent of consultations pre-COVID-19 to over 40 per cent during the pandemic. While the data for general practice in Ireland is much poorer than in England, there is evidence from Collins and Homeniuk (2021) and the Medical Council that similar increases in telemedicine occurred in general practice in Ireland.

A key concern is that, with increased use of digital health, individuals' personal data should be protected. In 2020 the Council of Europe published a 'Digital Solutions to fight COVID-19: 2020 data protection' report (Council of Europe, 2020). It stated: 'This quantum-leap in the digitalisation of our lives requires that measures adopted by governments during the health crisis uphold the protection of individuals with regard to the processing of personal data. Privacy and data protection have a pivotal role, essential in building and sustaining trust in digital solutions' (Council of Europe, 2020).

\subsection{POLICY RECOMMENDATIONS}

Below we provide recommendations to policymakers on HIS, health data infrastructure and health informatics, based on findings in this report. It is important to note that the development of an adequate HIS in Ireland will be a long-term process. Many recommendations can be implemented quickly, while others will be longer-term projects. Furthermore, as technologies continue to evolve, so too will the potential of HIS and health informatics. Many of the points are similar to recent recommendations published for the NHS (Sheikh et al., 2021). Our recommendations are:

- Development of a nationwide HIS, with a robust data health infrastructure inputting into this system. This will lead to the widespread adoption of the IHI and, in time, a national EHR across public and private health systems. Standards must be set so that information recorded is as complete as possible, accessible to the relevant parties and standardised for comparative purposes (HIQA, 2014; 2015b).

- The health data infrastructure should be robust, structured and rigorous, 
capturing data from public and private providers to allow for resource, capacity, and workforce planning.

- Privacy protections for data subjects and cybersecurity provisions must continue to be developed in accordance with relevant legislation and General Data Protection Regulation (GDPR). This process should be transparent and well communicated to the public.

- Continued investment in current and capital ICT and eHealth funding. Antiquated healthcare technologies should be replaced with technologies and systems that ensure modern capabilities and functions.

- Health literacy should be promoted so that the general public understand the benefits of eHealth, and how to use eHealth services. Specific supports will be needed for vulnerable populations such as older people and those with lower digital literacy. Consideration must be given to the connectivity of those in rural areas and in lower socioeconomic groups.

- The healthcare workforce is a key factor in the successful integration of a HIS. Supporting and training the healthcare workforce is necessitated to allow for the adoption of new health technologies and eHealth. 


\section{REFERENCES}

Abou-Khalil, B., P. Auce, A. Avbersek, M. Bahlo, D.J. Balding, T. Bast, L. Baum, A.J. Becker, F. Becker, B. Berghuis, et al. (2018). "Genome-wide mega-analysis identifies 16 loci and highlights diverse biological mechanisms in the common epilepsies." Nature Communications 9(1): 5269. 10.1038/s41467-018-07524-z.

Aceto, G., Persico, V., Pescapé, A. (2020). Industry 4.0 and Health: Internet of Things, Big Data, and Cloud Computing for Healthcare 4.0. Journal of Industrial Information Integration 18, 100129. https://doi.org/10.1016/j.jii.2020.100129

Allin, S., G. Marchildon and A. Peckham (2020). International Health Care System Profiles: Canada. In: R. Tikkanen, R. Osborn, E. Mossialos, A. Djordjevic and G. A. Wharton (eds.) International Health Care System Profiles. The Commonwealth Fund.

Athey, S. (2017). "Beyond prediction: Using big data for policy problems." Science 355(6324): 483-485. 10.1126/science.aal4321.

Baig, M.M., H. GholamHosseini, A.A. Moqeem, F. Mirza and M. Lindén (2017). "A Systematic Review of Wearable Patient Monitoring Systems - Current Challenges and Opportunities for Clinical Adoption." Journal of Medical Systems 41(7): 115. 10.1007/s10916-017-0760-1.

Bakhai, M., L. Croney, O. Waller, N. Henshall and C. Felstead (2020). Using Online Consultations In Primary Care, NHS England. https://www.england.nhs.uk/wpcontent/uploads/2020/01/online-consultations-implementation-toolkit-v1.1updated.pdf.

Bakken, S. (2020). Informatics is a critical strategy in combating the COVID-19 pandemic. Journal of the American Medical Informatics Association 27, 843-844. https://doi.org/10.1093/jamia/ocaa101

Bakken, S. (2021). Biomedical and health informatics approaches remain essential for addressing the COVID-19 pandemic. Journal of the American Medical Informatics Association, ocab007. https://doi.org/10.1093/jamia/ocab007

Banks, J., D. Corrigan, R. Grogan, H. El-Naggar, M. White, E. Doran, C. Synnott, M. Fitzsimons, N. Delanty and C.P. Doherty (2021). "LoVE in a time of CoVID: Clinician and patient experience using telemedicine for chronic epilepsy management." Epilepsy Behav 115: 107675. 10.1016/j.yebeh.2020.107675.

Bath, P.A. (2008). Health informatics: current issues and challenges. Journal of Information Science 34, 501-518. https://doi.org/10.1177/0165551508092267.

Beeching, N.J., Fletcher, T.E., Beadsworth, M.B.J. (2020). COVID-19: testing times. BMJ m1403. https://doi.org/10.1136/bmj.m1403

Boland, M.R.S., A.L. Kruis, A. Tsiachristas, W.J.J. Assendelft, J. Gussekloo, C.M.G. Blom, N.H. Chavannes and M.P.M.H. Rutten-van Mölken (2015). "Cost-effectiveness of integrated COPD care: the RECODE cluster randomised trial." BMJ Open 5(10): e007284. 10.1136/bmjopen-2014-007284.

Bossen, C., Pine, K.H., Cabitza, F., Ellingsen, G., Piras, E.M. (2019). Data work in healthcare: An Introduction. Health Informatics J, 25, 465-474.

https://doi.org/10.1177/1460458219864730 
Brick, A. and S. Connolly (2021). "Waiting Times for Publicly Funded Hospital Treatment: How does Ireland Measure Up?" The Economic and Social Review 52(1): 41-52.

Brick, A., B. Walsh, C. Keegan and S. Lyons (2020b). COVID-19 and emergency department attendances in Irish public hospitals. QEC Special Article. ESRI, Dublin. https://doi.org/10.26504/qec2020may_SA_lyons.

Brick, A., C. Keegan and M.A. Wren (2020a). Utilisation of Specialist Mental Health Services in Ireland - Baseline Analysis for the Hippocrates Model. Survey and Statistical Report Series Number 90. Economic and Social Research Institute, Dublin. https://doi.org/10.26504/sustat90.

Busby, J., S. Purdy and W. Hollingworth (2017). "Calculating hospital length of stay using the Hospital Episode Statistics; a comparison of methodologies." BMC Health Services Research 17(1): 347-347. 10.1186/s12913-017-2295-z.

Canada Health Infoway (2020). Connecting Canadians through health care innovation: Canada Health Infoway Annual Report 2019-2020. Canada Health Infoway, Montreal.

Cancino, R.S., Z. Su, R. Mesa, G.E. Tomlinson and J. Wang (2020). "The Impact of COVID-19 on Cancer Screening: Challenges and Opportunities." JMIR Cancer 6(2): e21697. $10.2196 / 21697$.

Cantor, J.H., R.K. McBain, M.F. Pera, D.M. Bravata and C.M. Whaley (2021). "Who Is (and Is Not) Receiving Telemedicine Care During the COVID-19 Pandemic." Am J Prev Med. 10.1016/j.amepre.2021.01.030.

Carolan, J. (2018). Addressing the challenges of delivering healthcare innovation. Individual Health Identifier $(\mathrm{IHI})$, eHealth Ireland \& Northern Ireland Connected Health Ecosystems - 2nd Joint Gathering. Trinity Biomedical Sciences Institute, Trinity College Dublin.

Chang, F., Gupta, N. (2015). Progress in electronic medical record adoption in Canada. Canadian Family Physician 61, 1076-1084.

Chin, A., G.L. Simon, P. Anthamatten, K.C. Kelsey, B.R. Crawford and A.J. Weaver (2020). "Pandemics and the future of human-landscape interactions." Anthropocene 31: 100256. https://doi.org/10.1016/j.ancene.2020.100256.

Clifton, D.A., Niehaus, K.E., Charlton, P., Colopy, G.W. (2015). Health Informatics via Machine Learning for the Clinical Management of Patients. Yearb Med Inform 24, 38-43. https://doi.org/10.15265/IY-2015-014

Collins, C. and R. Homeniuk (2021). "How many general practice consultations occur in Ireland annually? Cross-sectional data from a survey of general practices." BMC Family Practice 22(1): 40. 10.1186/s12875-021-01377-0.

Colombo, F., Oderkirk, J., Slawomirski, L. (2020). Health Information Systems, Electronic Medical Records, and Big Data in Global Healthcare: Progress and Challenges in OECD Countries, in: Haring, R., Kickbusch, I., Ganten, D., Moeti, M. (Eds.), Handbook of Global Health. Springer International Publishing, Cham, pp. 1-31. https://doi.org/10.1007/978-3-030-05325-3_71-1

Community Preventive Services Task Force (2015). Recommendation for Use of Immunization Information Systems to Increase Vaccination Rates. Journal of 
Public Health Management and Practice 21, 249-252. https://doi.org/10.1097/PHH.0000000000000092

Connolly, S., A. Nolan, B. Walsh and M. Wren (2018). "Universal GP Care in Ireland: Potential Cost Implications." Econ Soc Rev 49(1): 93-91.99, https://www.esr.ie/article/view/871.

Council of Europe (2020). "DIGITAL SOLUTIONS TO FIGHT COVID-19", 2020 DATA PROTECTION REPORT, https://rm.coe.int/prems-120820-gbr-2051-digitalsolutions-to-fight-covid-19-text-a4-web-/16809fe49c.

Cresswell, K., Callaghan, M., Khan, S., Sheikh, Z., Mozaffar, H., Sheikh, A. (2020). Investigating the use of data-driven artificial intelligence in computerised decision support systems for health and social care: A systematic review. Health Informatics J 26, 2138-2147. https://doi.org/10.1177/1460458219900452

Cresswell, K., R. Williams and A. Sheikh (2021). "Using cloud technology in health care during the COVID-19 pandemic." The Lancet Digital Health 3(1): e4-e5. 10.1016/S2589-7500(20)30291-0.

Crowe Horwatch (2018). Report on the Role, Training and Career Structures of Public Health Physicians in Ireland. Department of Health, https://assets.gov.ie/9446/56efd96dac314a9692b785706b5a5ecb.pdf.

Crowley, P. and A. Hughes (2021). The impact of COVID-19 pandemic and the societal restrictions on health and wellbeing on service capacity and delivery: A plan for health care and population health recovery, Dublin: National QI Team, Health Service Executive, https://www.hse.ie/eng/about/who/qid/COVID-19-qilearning/qi-resources-to-support-learning-from-covid19/COVID-19-pandemicimpact-paper-2021.pdf

Dagliati, A., Malovini, A., Tibollo, V., Bellazzi, R. (2021). Health informatics and EHR to support clinical research in the COVID-19 pandemic: an overview. Briefings in Bioinformatics bbaa418. https://doi.org/10.1093/bib/bbaa418

de Lusignan, S., Jones, N., Dorward, J., Byford, et al. (2020). The Oxford Royal College of General Practitioners Clinical Informatics Digital Hub: Protocol to Develop Extended COVID-19 Surveillance and Trial Platforms. JMIR Public Health Surveill 6, e19773. https://doi.org/10.2196/19773

Deloitte \& Touche (2015). Independent review of New Zealand's electronic health records strategy. Ministry of Health, New Zealand.

Department of Health (2013). eHealth Strategy for Ireland, https://www.ehealthireland.ie/knowledge-information-plan/ehealth-strategyfor-ireland.pdf.

Department of Health (2019). Sláintecare Action Plan 2019. Department of Health, Dublin. https://assets.gov.ie/9379/05384619bb2240c18c294b60578117e1.pdf.

Department of Health (2018). Sláintecare Implementation Strategy. Department of Health, Dublin.

Devin, J., B.J. Cleary and S. Cullinan (2020). "The impact of health information technology on prescribing errors in hospitals: a systematic review and behaviour change technique analysis." Syst Rev 9(1): 275. 10.1186/s13643-020-01510-7. 
Devin, J., J. Costello, N. McCallion, E. Higgins, B. Kehoe, B.J. Cleary and S. Cullinan (2021). "Impact of an electronic health record on task time distribution in a neonatal intensive care unit." Int J Med Inform 145: 104307. 10.1016/j.ijmedinf.2020.104307.

Dixon, B.E., Grannis, S.J., McAndrews, C., Broyles, A.A., Mikels-Carrasco, W., Wiensch, A., Williams, J.L., Tachinardi, U., Embi, P.J. (2021). Leveraging data visualization and a statewide health information exchange to support COVID-19 surveillance and response: Application of public health informatics. Journal of the American Medical Informatics Association ocab004. https://doi.org/10.1093/jamia/ocab004

Dorr, D., Bonner, L.M., Cohen, A.N., Shoai, R.S., Perrin, R., Chaney, E., Young, A.S. (2007). Informatics Systems to Promote Improved Care for Chronic Illness: A Literature Review. Journal of the American Medical Informatics Association 14, 156-163. https://doi.org/10.1197/jamia.M2255

Dreyer, K., W. Parry, W. Jayatunga and S. Deeny (2019). "A descriptive analysis of health care use by highcost, high-need patients in England." Health Foundation working paper. https://www.health.org.uk/sites/default/files/upload/publications/2019/Healthcare-use-by-high-cost-high-need-patients-WP07.pdf.

EC (2012). eHealth Action Plan 2012-2020 - Innovative healthcare for the 21st century. Communication from the Commission to the European Parliament, the Council, the European Economic and Social Committee and the Committee of the Regions (No. 736). European Commission, Brussels.

EC (2020a). eHealth: Digital health and care [WWW Document]. European Commission. https://ec.europa.eu/health/ehealth/electronic_crossborder_healthservices_en.

EC (2020b). Coronavirus: Commission starts testing interoperability gateway service for national contact tracing and warning apps [WWW Document]. European Commission.

https://ec.europa.eu/commission/presscorner/detail/en/IP_20_1606.

e-Estonia (2021). e-Health Record. https://e-estonia.com/solutions/healthcare/e-healthrecord/.

eHealth Network (2020). Mobile applications to support contact tracing in the EU's fight against COVID-19: Common EU Toolbox for Member States.

Eighan, J., S. Smith, M.-A. Wren, E. Morgenroth and B. Walsh (2017). A Profile of Public and Private Physiotherapy Supply in Ireland, forthcoming working paper. Economic and Social Research Institute, Dublin, Ireland.

Faculty of Pathology Ireland (2020). Deploying Data-Driven Intelligence to measure the impact of COVID-19 on cancer care and cancer patients, Dublin: Royal College of Physicians in Ireland.

Farrell, S., Leith D. (2021). Irish Covidtracker App Key Upload Shortfalls. School of Science and Statistics, Trinity College Dublin.

Ferrone, M., M.G. Masciantonio, N. Malus, L. Stitt, T. O'Callahan, Z. Roberts, L. Johnson, J. Samson, L. Durocher, M. Ferrari, et al. (2019). "The impact of integrated disease management in high-risk COPD patients in primary care." npj Primary Care Respiratory Medicine 29(1): 8. 10.1038/s41533-019-0119-9. 
Ford, D., Harvey, J.B., McElligott, J., King, K., Simpson, K.N., Valenta, S., Warr, E.H., Walsh, T., Debenham, E., Teasdale, C., Meystre, S., Obeid, J.S., Lenert, L.A.(2020). Leveraging Health System Telehealth and Informatics Infrastructure to Create a Continuum of Services for COVID-19 Screening, Testing, and Treatment. Journal of the American Medical Informatics Association ocaa157. https://doi.org/10.1093/jamia/ocaa157.

Fuller, M.J., Ahmad, M.K.S. (2017). Malaysian Health Data Warehouse (MyHDW). 20152016 Start-up: Initiation. Health Informatics Centre, Ministry of Health Malaysia, Putrajaya.

Grange, E.S., Neil, E.J., Stoffel, M., Singh, A.P., Tseng, E., Resco-Summers, K., Fellner, B.J., Lynch, J.B., Mathias, P.C., Mauritz-Miller, K., Sutton, P.R., Leu, M.G. (2020). Responding to COVID-19: The UW Medicine Information Technology Services Experience. Appl Clin Inform 11, 265-275. https://doi.org/10.1055/s-00401709715.

Greenhalgh, T., G.C.H. Koh and J. Car (2020). "Covid-19: a remote assessment in primary care." BMJ 368: m1182. 10.1136/bmj.m1182.

Griebel, L., Prokosch, H.-U., Köpcke, F., Toddenroth, D., Christoph, J., Leb, I., Engel, I., Sedlmayr, M. (2015). A scoping review of cloud computing in healthcare. BMCMed Inform Decis Mak 15, 17. https://doi.org/10.1186/s12911-015-0145-7

Habicht, T., M. Reinap, K. Kasekamp, R. Sikkut, L. Aaben and E. van Ginneken (2018). "Estonia: Health System Review." Health Syst Transit 20(1): 1-189.

Hamann, D.J., Bezboruah, K.C. (2020). Outcomes of health information technology utilization in nursing homes: Do implementation processes matter? Health Informatics J 26, 2249-2264. https://doi.org/10.1177/1460458219899556

Hanratty, B., Burton, J.K., Goodman, C., Gordon, A.L., Spilsbury, K. (2020). COVID-19 and lack of linked datasets for care homes. BMJ m2463. https://doi.org/10.1136/bmj.m2463

Harmon, C. and B. Nolan (2001). "Health insurance and health services utilization in Ireland." Health Econ 10(2): 135-145.

Hashiguchi, T.C.O. (2020). "Bringing health care to the patient: An overview of the use of telemedicine in OECD countries", OECD Health Working Paper No 116, https://www.oecd.org/officialdocuments/publicdisplaydocumentpdf/?cote=DELS A/HEA/WD/HWP(2020)1\&docLanguage=En.

Healthcare Pricing Office (2018). Hospital In-Patient Enquiry (HIPE): Data Dictionary 2018 Version 10.0. Health Service Executive, Dublin.

HIQA (2009). Recommendations for a Unique Health Identifier for Individuals in Ireland.

H. I. a. Q. Authority, https://www.hiqa.ie/sites/default/files/2017-

02/Unique_Health_Identifier_Report\%20(1).pdf.

HIQA (2014). International review of approaches countries have taken to integrate National Health and Social Care Data Collections. H. I. a. Q. Authority, https://www.hiqa.ie/sites/default/files/2017-01/International-review-NationalHealth-Social-Care-Data-Collections.pdf.

HIQA (2015a). Draft information governance and management standards for the health identifiers operator in Ireland. Public consultation document. Health and 
Information Quality Authority, https://www.hiqa.ie/sites/default/files/201702/IG-and-M-Standards-for-Health-Identifiers-Operator\%20(1).pdf.

HIQA (2015b). Frequently asked questions about health identifiers. Health and Information Quality Authority, https://www.hiqa.ie/sites/default/files/2017-01/IGMStandards-for-HIO-FAQ.pdf.

HIQA (2018). Recommendations for the national, community-based ePrescribing programme in Ireland. health and Information Quality Authority, https://www.hiqa.ie/sites/default/files/2018-

10/EPrescribing_Recommendations.pdf.

HIQA (2020). Recommendations on the Implementation of a National Electronic Patient Summary in Ireland. Health and Information Quality Authority, https://www.hiqa.ie/sites/default/files/2021-

01/Recommendations_Implementation_PatientSummary_0.pdf.

HIQA (2016). International Review of National Summary Care Records. HIQA, Dublin.

HIQA (2018). Statement of outcomes: Report on focus group discussions and public consultation on a National Standard on information requirements for a national electronic patient summary. HIQA, Dublin.

HIQA (2019). What is a National Electronic Patient Summary? HIQA, Dublin.

Holmgren, A.J., Apathy, N.C., Adler-Milstein, J. (2020). Barriers to hospital electronic public health reporting and implications for the COVID-19 pandemic. Journal of the American Medical Informatics Association 27, 1306-1309. https://doi.org/10.1093/jamia/ocaa112.

Homeniuk, R. and C. Collins (2021). "How COVID-19 has affected general practice consultations and income: general practitioner cross-sectional population survey evidence from Ireland". BMJ Open 11(4): e044685. 10.1136/bmjopen-2020044685.

Horton, T., T. Hardie, S. Mahadeva and W. Warburton (2021). "Securing a positive health care technology legacy from COVID-19". The Health Foundation, https://www.health.org.uk/sites/default/files/2021-

03/Securing\%20a\%20positive\%20technology\%20legacy\%20from\%20COVID19.pdf.

Houses of the Oireachtas Committee on the Future of Healthcare (2017). Sláintecare Report. Houses of the Oireachtas, Dublin, http://www.oireachtas.ie/parliament/media/committees/futureofhealthcare/Oir eachtas-Committee-on-the-Future-of-Healthcare-Slaintecare-Report-300517.pdf.

HSE (2013). eHealth Strategy for Ireland, Health Service Executive.

HSE (2015). Knowledge and Information Strategy: Delivering the Benefits of eHealth in Ireland. Health Service Executive, https://www.ehealthireland.ie/knowledgeinformation-plan/knowledge-and-information-plan.pdf.

HSE (2016). National Electronic Health Record: Strategic Business Case Health Service Executive, https://www.ehealthireland.ie/strategic-programmes/electronichealth-record-ehr-/progress/national-business-case.pdf. 
Ismail, N.I., Abdullah, N.H., Shamsuddin, A. (2015). Adoption of Hospital Information System (HIS) in Malaysian Public Hospitals. Procedia - Social and Behavioral Sciences 172, 336-343. https://doi.org/10.1016/j.sbspro.2015.01.373.

Jefferies, S., N. French, C. Gilkison, G. Graham, V. Hope, J. Marshall, C. McElnay, A. McNeill, P. Muellner, S. Paine, et al. (2020). "COVID-19 in New Zealand and the impact of the national response: a descriptive epidemiological study". The Lancet Public Health 5(11): e612-e623. 10.1016/S2468-2667(20)30225-5.

Jensen, P.B., Jensen, L.J., Brunak, S. (2012). Mining electronic health records: towards better research applications and clinical care. Nat Rev Genet 13, 395-405. https://doi.org/10.1038/nrg3208.

Judson, T.J., Odisho, A.Y., Neinstein, A.B., Chao, J., Williams, A., Miller, C., Moriarty, T., Gleason, N., Intinarelli, G., Gonzales, R. (2020). Rapid design and implementation of an integrated patient self-triage and self-scheduling tool for COVID-19. Journal of the American Medical Informatics Association 27, 860-866. https://doi.org/10.1093/jamia/ocaa051.

Kapur, K. (2019). "Private health insurance in Ireland: Trends and determinants". UCD School of Economics Working Papers 201903, https://ideas.repec.org/p/ucn/wpaper/201903.html.

Keane, C., M. Regan and B. Walsh (2021). "Failure to Take-Up Public Healthcare Entitlements: Evidence from the Medical Card System in Ireland". Social Science and Medicine, forthcoming.

Keegan, C. and S. Lyons (2021a). Hospital admission probability and length of stay among Covid-19 confirmed cases. Irish Epidemiological Modelling Advisory Group, https://assets.gov.ie/125771/11f37052-d28e-4cde-b747-99e59be75ca3.pdf.

Keegan, C. and S. Lyons (2021b). COVID-19 Hospital Utilisation Planning model: description and parameters. Irish Epidemiological Modelling Advisory Group, https://assets.gov.ie/125113/9837732e-4401-424b-a703-d5f8634a2e33.pdf.

Kennelly, B., M. O'Callaghan, D. Coughlan, J. Cullinan, E. Doherty, L. Glynn, E. Moloney and M. Queally (2020). "The COVID-19 pandemic in Ireland: An overview of the health service and economic policy response", Health Policy and Technology 9(4): 419429. 10.1016/j.hlpt.2020.08.021.

Kraef, C., M. van der Meirschen and C. Free (2020). "Digital telemedicine interventions for patients with multimorbidity: a systematic review and meta-analysis." BMJ Open 10(10): e036904. 10.1136/bmjopen-2020-036904.

Kuo, A.M.-H., 2011. Opportunities and Challenges of Cloud Computing to Improve Health Care Services. J Med Internet Res 13, e67. https://doi.org/10.2196/jmir.1867

Larkin, J., Pericin, I., Collins, C. (2017). Healthmail Evaluation Report. Irish College of General Practitioners, Dublin.

Lau, F., Price, M., Keshavjee, K. (2011). From Benefits Evaluation to Clinical Adoption: Making Sense of Health Information System Success in Canada. Healthcare Quarterly 14, 39-45.

Lenert, L., McSwain, B.Y. (2020). Balancing health privacy, health information exchange, and research in the context of the COVID-19 pandemic. Journal of the American 
Medical Informatics Association 27, 963-966.

https://doi.org/10.1093/jamia/ocaa039.

Li, D., Chao, J., Kong, J., Cao, G., Lv, M., Zhang, M. (2020). The efficiency analysis and spatial implications of health information technology: A regional exploratory study in China. Health Informatics J 26, 1700-1713.

https://doi.org/10.1177/1460458219889794

Li, X., H.M. Krumholz, W. Yip, K.K. Cheng, J. De Maeseneer, Q. Meng, E. Mossialos, C. Li, J. Lu, M. Su, et al. (2020). "Quality of primary health care in China: challenges and recommendations." The Lancet 395(10239): 1802-1812. 10.1016/S01406736(20)30122-7.

Liang, J., Li, Y., Zhang, Z., Shen, D., Xu, J., Yu, G., Dai, S., Ge, F., Lei, J. (2020). Evaluating the Applications of Health Information Technologies in China During the Past 11 Years: Consecutive Survey Data Analysis. JMIR Med Inform 8, e17006. https://doi.org/10.2196/17006

Lin, C.-T., Bookman, K., Sieja, A., Markley, K., Altman, R.L., Sippel, J., Perica, K., Reece, L., Davis, C., Horowitz, E., Pisney, L., Sottile, P.D., Kao, D., Adrian, B., Szkil, M., Griffin, J., Youngwerth, J., Drew, B., Pell, J. (2020). Clinical informatics accelerates health system adaptation to the COVID-19 pandemic: examples from Colorado. Journal of the American Medical Informatics Association 27, 1955-1963. https://doi.org/10.1093/jamia/ocaa171.

Lynch, M. and A.C. O'Leary (2021). "COVID-19 related regulatory change for pharmacists The case for its retention post the pandemic." Research in Social \& Administrative Pharmacy: RSAP 17(1): 1913-1919. 10.1016/j.sapharm.2020.07.037.

Madurai Elavarasan, R., Pugazhendhi, R. (2020). Restructured society and environment: A review on potential technological strategies to control the COVID-19 pandemic. Science of the Total Environment 725, 138858. https://doi.org/10.1016/j.scitotenv.2020.138858.

Martin, D.W., Lowery, N.E., Brand, B., Gold, R., Horlick, G. (2015). Immunization Information Systems: A Decade of Progress in Law and Policy. Journal of Public Health Management and Practice 21, 296-303. https://doi.org/10.1097/PHH.0000000000000040.

Martin, P.M., Sbaffi, L. (2020). Electronic Health Record and Problem Lists in Leeds, United Kingdom: Variability of general practitioners' views. Health Informatics J 26, 18981911. https://doi.org/10.1177/1460458219895184.

Marzal-Alfaro, Mb., Rodriguez-Gonzalez, C.G., Escudero-Vilaplana, V., Revuelta-Herrero, J.L., González-Haba, E., Ibáñez-Garcia, S., Iglesias-Peinado, I., Herranz-Alonso, A., Sanjurjo Saez, M. (2020). Risks and medication errors analysis to evaluate the impact of a chemotherapy compounding workflow management system on cancer patients' safety. Health Informatics J 26, 1995-2010. https://doi.org/10.1177/1460458219895434.

Medical Council of Ireland (2020). Telemedicine. Phone and Video Consultations: A guide for doctors, https://www.medicalcouncil.ie/public-information/telemedicinephone-and-video-consultations-guide-for-patients/telemedicine-for-doctorsbooklet.pdf. 
Medical Independent (2015). Telemedicine does not meet standards of best GP provisionICGP. The Medical Independent.

Mell, P., Grance, T. (2011). The NIST Definition of Cloud Computing: Recommendations of the National Institute of Standards and Technology.

MillwardBrown (2016). Health Insurance Authority - A Review of Private Health Insurance in Ireland. The Health Insurance Authority, http://www.hia.ie/publication/consumer-surveys.

Monaghesh, E. and A. Hajizadeh (2020). "The role of telehealth during COVID-19 outbreak: a systematic review based on current evidence." BMC Public Health 20(1): 1193. 10.1186/s12889-020-09301-4.

Mullainathan, S. and J. Spiess (2017). "Machine Learning: An Applied Econometric Approach." Journal of Economic Perspectives 31(2): 87-106. 10.1257/jep.31.2.87.

Murtagh, S., G. McCombe, J. Broughan, Á. Carroll, M. Casey, Á. Harrold, T. Dennehy, R. Fawsitt and W. Cullen (2021). "Integrating Primary and Secondary Care to Enhance Chronic Disease Management: A Scoping Review." International Journal of Integrated Care 21(1): 4. http://doi.org/10.5334/ijic.5508.

NEJM Catalyst (2018). "Healthcare Big Data and the Promise of Value-Based Care." NEJM Catalyst. Innovations in Care Delivery, https://catalyst.nejm.org/doi/full/10.1056/CAT.18.0290.

New Zealand Ministry of Health (2018). National Health Index overview [WWW Document]. Ministry of Health. URL https://www.health.govt.nz/our-work/healthidentity/national-health-index/national-health-index-overview.

NHS Digital (2018). Data, insights and statistics. NHS Digital. https://digital.nhs.uk/dataand-information/data-insights-and-statistics.

NHS Digital (2019). Spine. NHS Digital. https://digital.nhs.uk/services/spine.

NHS Digital (2020). Summary Care Records (SCR) [WWW Document]. NHS Digital. https://digital.nhs.uk/services/summary-care-records-

scr\#: :text=Summary\%20Care\%20Records\%20(SCR)\%20are,in\%20the\%20patient' s\%20direct\%20care.

NHS England (2020). NHS Long Term Plan: Chapter 5: Digitally-enabled care will go mainstream across the NHS. https://www.longtermplan.nhs.uk/onlineversion/chapter-5-digitally-enabled-care-will-go-mainstream-across-the-nhs/.

NHS Scotland (2021). Electronic Health Records.

https://www.nhsresearchscotland.org.uk/research-in-scotland/data/sub-page-4.

NICE (2021). Artificial intelligence in mammography: Medtech innovation briefing [MIB242]. National Institute for Health and Care Excellence, https://www.nice.org.uk/advice/mib242/chapter/Thetechnologies\#healthmammo-software-zebra-medical-vision.

Niyirora, J., Aragones, O. (2020). Network analysis of medical care services. Health Informatics J 26, 1631-1658. https://doi.org/10.1177/1460458219887047. 
Nolan, A. (2014). Health: Funding, Access and Efficiency, in: O'Hagan, J., Newman, C. (Eds.), The Economy of Ireland: National and Sectoral Policy Issues. Gill and Macmillan, Dublin, pp. 314-337.

Nolan, A., S. Barry, S. Burke and S. Thomas (2014). The impact of the financial crisis on the health system and health in Ireland. European Observatory on Health Systems and Policies.

O'Reilly, D., H. Carroll, M. Lucas, J. Sui, M. Al Sendi, D. McMahon, W. Darwish, R. McLaughlin, M.R. Khan, H.O. Sullivan, et al. (2021). "Virtual oncology clinics during the COVID-19 pandemic." Irish Journal of Medical Science (1971-). 10.1007/s11845-020-02489-9.

O'Reilly-Shah, V.N., Gentry, K.R., Van Cleve, W., Kendale, S.M., Jabaley, C.S., Long, D.R. (2020). The COVID-19 Pandemic Highlights Shortcomings in US Health Care Informatics Infrastructure: A Call to Action. Anesthesia \& Analgesia 131, 340-344. https://doi.org/10.1213/ANE.0000000000004945.

Oderkirk, J. (2017). "Readiness of electronic health record systems to contribute to national health information and research." doi:https://doi.org/10.1787/9e296bf3-en.

OECD (2013). OECD Reviews of Health Care Quality: Denmark. OECD, https://www.oecd.org/els/health-

systems/ReviewofHealthCareQualityDENMARK_ExecutiveSummary.pdf.

PA Consulting (2018). Health Service Capacity Review 2018. Department of Health, Department of Health, Dublin, Ireland.

Peng, C., Goswami, P., Bai, G. (2020). A literature review of current technologies on health data integration for patient-centered health management. Health Informatics J 26, 1926-1951. https://doi.org/10.1177/1460458219892387

Porter, M., Kellogg, M. (2008). Kaiser Permanente: an integrated health care experience. Revista de Innovación Sanitaria y Atención Integrada 1, 5.

Power, K., Z. McCrea, M. White, A. Breen, B. Dunleavy, S. O'Donoghue, T. Jacquemard, V. Lambert, H. El-Naggar, N. Delanty, et al. (2020). "The development of an epilepsy electronic patient portal: Facilitating both patient empowerment and remote clinician-patient interaction in a post-COVID-19 world." Epilepsia 61(9): 1894-1905. https://doi.org/10.1111/epi.16627.

Primary Care Partnership (2016). Primary Care: A framework for the future, https://www.icgp.ie/speck/properties/asset/asset.cfm?type=LibraryAsset\&id=03 FA84D1\%2DD6C0\%2DCCAC\%2D246A4E8DA77E788A\&property=asset\&revision=ti p\&disposition=inline\&app=icgp\&filename=PrimaryCarePartnership\%2Epdf.

Raisaro, J.L., Marino, F., Troncoso-Pastoriza, J., et al. (2020). SCOR: A secure international informatics infrastructure to investigate COVID-19. Journal of the American Medical Informatics Association 27, 1721-1726.

https://doi.org/10.1093/jamia/ocaa172.

Reeves, J.J., Hollandsworth, H.M., Torriani, F.J., Taplitz, R., Abeles, S., Tai-Seale, M., Millen, M., Clay, B.J., Longhurst, C.A. (2020). Rapid response to COVID-19: health informatics support for outbreak management in an academic health system. Journal of the American Medical Informatics Association 27, 853-859. https://doi.org/10.1093/jamia/ocaa037. 
Reilly, C. (2019). Telemedicine services strongly criticised by Medical Council President. The Medical Independent.

Rieke, N., J. Hancox, W. Li, F. Milletarì, H.R. Roth, S. Albarqouni, S. Bakas, M.N. Galtier, B.A. Landman, K. Maier-Hein, et al. (2020). "The future of digital health with federated learning." npj Digital Medicine 3(1): 119. 10.1038/s41746-020-00323-1.

Salath, M., Althaus, C.L., Neher, R., Stringhini, S., Hodcroft, E., Fellay, J., Zwahlen, M., Senti, G., Battegay, M., Wilder-Smith, A., Eckerle, I., Egger, M., Low, N. (2020). COVID-19 epidemic in Switzerland: on the importance of testing, contact tracing and isolation. Swiss Med Wkly. https://doi.org/10.4414/smw.2020.20225

Samuels-Kalow, M., T. Jaffe and K. Zachrison (2021). "Digital disparities: designing telemedicine systems with a health equity aim." Emergency Medicine Journal: emermed-2020-210896. 10.1136/emermed-2020-210896.

Schüssler-Fiorenza Rose, S.M., K. Contrepois, K.J. Moneghetti, W. Zhou, T. Mishra, S. Mataraso, O. Dagan-Rosenfeld, A.B. Ganz, J. Dunn, D. Hornburg, et al. (2019). "A longitudinal big data approach for precision health." Nature Medicine 25(5): 792804. 10.1038/s41591-019-0414-6.

Scottish Government (2013). The use of the $\mathrm{CHI}$ (Community Health Index) to support integrated care across the NHS in Scotland.

Shah, G.H., Leider, J.P., Castrucci, B.C., Williams, K.S., Luo, H. (2016). Characteristics of Local Health Departments Associated with Implementation of Electronic Health Records and other Informatics Systems. Public Health Rep 131, 272-282. https://doi.org/10.1177/003335491613100211.

Sheikh, A., M. Anderson, Albala, S., Casadei, B., Franklin, B.D., Richards, M., Taylor, D., Tibble, H., Mossialos, E. (2021). "Health information technology and digital innovation for national learning health and care systems". The Lancet Digital Health. 10.1016/S2589-7500(21)00005-4.

Sittig, D.F., Singh, H. (2020). COVID-19 and the Need for a National Health Information Technology Infrastructure. JAMA 323, 2373. https://doi.org/10.1001/jama.2020.7239.

Smith, A.C., E. Thomas, C.L. Snoswell, H. Haydon, A. Mehrotra, J. Clemensen and L.J. Caffery (2020). "Telehealth for global emergencies: Implications for coronavirus disease 2019 (COVID-19)." Journal of Telemedicine and Telecare 26(5): 309-313. $10.1177 / 1357633 \times 20916567$.

Smith, S., S. Barron, M.-A. Wren, B. Walsh, E. Morgenroth, J. Eighan and S. Lyons (2019). Geographic Profile of Healthcare Needs and Non-Acute Healthcare Supply in Ireland. ESRI Research Series No. 90, https://www.esri.ie/publications/geographicprofile-of-healthcare-needs-and-non-acute-healthcare-supply-in-ireland.

Spronck, R. (2008). AORTA, the Dutch national infrastructure. Whitepaper. Ringholm.

Stamenova, V., P. Agarwal, L. Kelley, J. Fujioka, M. Nguyen, M. Phung, I. Wong, N. Onabajo, R.S. Bhatia and O. Bhattacharyya (2020). "Uptake and patient and provider communication modality preferences of virtual visits in primary care: a retrospective cohort study in Canada." BMJ Open 10(7): e037064. 10.1136/bmjopen-2020-037064. 
Stokes, J., B. Guthrie, S.W. Mercer, N. Rice and M. Sutton (2021). "Multimorbidity combinations, costs of hospital care and potentially preventable emergency admissions in England: A cohort study." PLOS Medicine 18(1): e1003514. 10.1371/journal.pmed.1003514.

Subash, M., Sakumoto, M., Bass, J., Hong, P., Muniyappa, A., Pierce, L., Purmal, C., Ramaswamy, P., Sono, R., Uptegraft, C., Feinstein, D., Khanna, R. (2020). The emerging role of clinical informatics fellows in service learning during the COVID19 pandemic. Journal of the American Medical Informatics Association ocaa241. https://doi.org/10.1093/jamia/ocaa241.

Subbian, V., Solomonides, A., Clarkson, M., Rahimzadeh, V.N., Petersen, C., Schreiber, R., DeMuro, P.R., Dua, P., Goodman, K.W., Kaplan, B., Koppel, R., Lehmann, C.U., Pan, E., Senathirajah, Y. (2021). Ethics and informatics in the age of COVID-19: challenges and recommendations for public health organization and public policy. Journal of the American Medical Informatics Association 28, 184-189. https://doi.org/10.1093/jamia/ocaa188

Sylvestre, E., Thuny, R.-M., Cecilia-Joseph, E., Gueye, P., Chabartier, C., Brouste, Y., Mehdaoui, H., Najioullah, F., Pierre-François, S., Abel, S., Cabié, A., Dramé, M. (2020). Health informatics support for outbreak management: How to respond without an electronic health record? Journal of the American Medical Informatics Association 27, 1828-1829. https://doi.org/10.1093/jamia/ocaa183.

Ton, A.N., Jethwa, T., Waters, K., Speicher, L.L., Francis, D. (2020). COVID-19 drive through testing: An effective strategy for conserving personal protective equipment. American Journal of Infection Control 48, 731-732. https://doi.org/10.1016/j.ajic.2020.04.010.

UK Department of Health and Social Care (2021). UK COVID-19 vaccines delivery plan.

Urquhart, G.A., Williams, W., Tobias, J., Welch, F.J. (2007). Immunization Information Systems Use During a Public Health Emergency in the United States. Journal of Public Health Management and Practice 13, 481-485. https://doi.org/10.1097/01.PHH.0000285201.54426.0c

Venkataraman, N., Poon, B.H., Siau, C. (2020). Innovative use of health informatics to augment contact tracing during the COVID-19 pandemic in an acute hospital. Journal of the American Medical Informatics Association 27, 1964-1967. https://doi.org/10.1093/jamia/ocaa184.

Walsh, B. and S. Lyons (2021). "Demand for the Statutory Home Support Scheme." ESRI Research Series Report Number 122. doi.org/10.26504/rs122.

Walsh, B., A. Nolan, A. Brick and C. Keegan (2019a). "Did the expansion of free GP care impact demand for Emergency Department attendances? A difference-indifferences analysis." Soc Sci Med 222: 101-111. https://doi.org/10.1016/j.socscimed.2018.12.029.

Walsh, B., C. Keegan, A. Brick and S. Lyons (2020). How is Ireland's healthcare system coping with coronavirus? Retrieved 22 October, 2020, https://www.coronavirusandtheeconomy.com/question/how-irelandshealthcare-system-coping-coronavirus. 
Walsh, B., M.-A. Wren, S. Smith, S. Lyons, J. Eighan and E. Morgenroth (2019b). An Analysis of the Effects on Irish Hospital Care of the Supply of Care Inside and Outside the Hospital. ESRI Research Series No. 91.

Weemaes, M., Martens, S., Cuypers, L., Van Elslande, J., Hoet, K., Welkenhuysen, J., Goossens, R., Wouters, S., Houben, E., Jeuris, K., Laenen, L., Bruyninckx, K., Beuselinck, K., André, E., Depypere, M., Desmet, S., Lagrou, K., Van Ranst, M., Verdonck, A.K.L.C., Goveia, J. (2020). Laboratory information system requirements to manage the COVID-19 pandemic: A report from the Belgian national reference testing center. Journal of the American Medical Informatics Association 27, 12931299. https://doi.org/10.1093/jamia/ocaa081

WHO (2020). Laboratory testing strategy recommendations for COVID-19.

Williamson, E.J., A.J. Walker, K. Bhaskaran, S. Bacon, C. Bates, C.E. Morton, H.J. Curtis, A. Mehrkar, D. Evans, P. Inglesby, et al. (2020). "Factors associated with COVID-19related death using OpenSAFELY." Nature 584(7821): 430-436. 10.1038/s41586020-2521-4.

Wise, J. (2020). Leicester lockdown: could better data have prevented it? BMJ m3028. https://doi.org/10.1136/bmj.m3028.

Wissel, B.D., Van Camp, P.J., Kouril, M., Weis, C., Glauser, T.A., White, P.S., Kohane, I.S., Dexheimer, J.W. (2020). An interactive online dashboard for tracking COVID-19 in U.S. counties, cities, and states in real time. Journal of the American Medical Informatics Association 27, 1121-1125. https://doi.org/10.1093/jamia/ocaa071.

Wootton, R. (2001). "Telemedicine." BMJ 323(7312): 557-560. 10.1136/bmj.323.7312.557.

Wren, M.-A. and A. Fitzpatrick (2020). How does Irish healthcare expenditure compare internationally? Economic and Social Research Institute, Dublin. Research Series Number 114.

Wren, M.A. and S. Connolly (2017). "A European late starter: lessons from the history of reform in Irish health care." Health Econ Policy Law: 1-19. https://doi.org/10.1017/\$1744133117000275.

Wren, M.A., C. Keegan, B. Walsh, A. Bergin, J. Eighan, A. Brick, S. Connolly, D. Watson and J. Banks (2017). Projections of Demand for Healthcare in Ireland, 2015-2030. First Report from the Hippocrates Model. ESRI Research Series No. 67. Economic and Social Research Institute, Dublin.

Wren, M.-A., S. Connolly and N. Cunningham (2015). An Examination of the Potential Costs of Universal Health Insurance in Ireland. ESRI Research Series No. 45. ESRI, ESRI, Dublin.

Wu, D., Hesketh, T., Shu, H., Lian, W., Tang, W., Tian, J. (2019). Description of an online hospital platform, China. Bull. World Health Organ. 97, 578-579. https://doi.org/10.2471/BLT.18.226936.

Ye, Q., Zhou, J., Wu, H. (2020). Using Information Technology to Manage the COVID-19 Pandemic: Development of a Technical Framework Based on Practical Experience in China. JMIR Med Inform 8, e19515. https://doi.org/10.2196/19515.

Zhou, W., M.R. Sailani, K. Contrepois, Y. Zhou, S. Ahadi, S.R. Leopold, M.J. Zhang, V. Rao, M. Avina, T. Mishra, et al. (2019). "Longitudinal multi-omics of host-microbe dynamics in prediabetes." Nature 569(7758): 663-671. 10.1038/s41586-019-1236-x. 
Zinsstag, J., J. Utzinger, N. Probst-Hensch, L. Shan and X.-N. Zhou (2020). "Towards integrated surveillance-response systems for the prevention of future pandemics." Infectious Diseases of Poverty 9(1): 140. 10.1186/s40249-020-00757-5. 
Whitaker Square,

Sir John Rogerson's Quay,

Dublin 2

Telephone +35318632000

Email admin@esri.ie

Web www.esri.ie

Twitter @ESRIDublin 